\title{
ESTUDIO DE COLOR DEL EDIFICIO DE LA FACULTAD DE ARQUITECTURA URBANISMO Y ARTES DE LA UNIVERSIDAD NACIONAL DE INGENIERÍA ${ }^{(*)}$
}

\author{
COLOR STUDY OF THE BUILDING OF THE FACULTY OF ARCHITECTURE, URBANISM AND \\ ARTS OF THE NATIONAL UNIVERSITY OF ENGINEERING
}

\author{
LORENA OLAZÁBAL FURUYA ${ }^{(\star)}$ \\ (D) https://orcid.org/0000-0003-1131-7639 \\ lyfuruya@gmail.com \\ Universidad de Piura (Perú) \\ Fecha de recepción: 2 de noviembre de 2019 \\ Fecha de aprobación: 2 de julio de 2020
}

\section{RESUMEN}

En el año 2017, se realizó el estudio de color del edificio de la Facultad de Arquitectura, Urbanismo y Artes (FAUA) con la finalidad de reconocer los diferentes estratos pictóricos subyacentes para poder conocer la paleta cromática empleada en el pintado de los inmuebles que corresponden a la FAUA a lo largo del tiempo. Esto ha permitido conocer los diversos usos y estilos cromáticos empleados, así como técnicas usadas y materiales empleados. Por otro lado, este tipo de prospección ha permitido definir el estado de conservación de ciertos estratos.

El uso de técnicas de prospección, como la elaboración de las calas estratigráficas permiten investigar y estudiar el bien inmueble como un documento histórico y a su vez dejar un vestigio sobre los cambios que se han suscitado a nivel estético y estilístico.

\section{PALABRAS CLAVE}

Color; técnicas de prospección; construcción histórica del edificio de la Facultad de Arquitectura; Urbanismo y Artes de la Universidad Nacional de Ingeniería

\begin{abstract}
In 2017, the color study of the building of Faculty of Architecture, Urbanism and Arts (FAUA) was carried out in order to recognize the different underlying pictorial strata to know the color palette used in the painting that correspond to the FAUA at the long of the time. This has allowed us to know the different uses and styles used, as well as used techniques and materials used. On the other hand, this type of prospecting has allowed defining the conservation status of certain strata.

The use of prospecting techniques, such as the elaboration of stratigraphic samples allow to investigate and study the real estate as a historical document and in turn leave a vestige on the changes that have occurred at the aesthetic and stylistic level.
\end{abstract}

\section{KEYWORDS}

Color; prospecting techniques; historic building of the Faculty of Architecture; Urbanism and Arts of the National University of Engineering

(*) El trabajo de estudio de color de la Facultad de Arquitectura, Urbanismo y Diseño fue realizado a pedido del Decanato a cargo del M Sc. Arq. José Beingolea en el año 2017. De esta manera se ha podido reconocer la importancia de identificar y estudiar los estratos subyacentes pictóricos para recuperar la paleta cromática de la facultad.

(**) Bachiller de Artes plásticas y visuales con mención en Conservación y restauración por la Escuela Nacional Superior de Bellas Artes del Perú. Cuenta con un máster propio de Patrimonio virtual de la Universidad de Alicante (2017), que la posiciona como especialista en conservación y restauración virtual y virtualización de patrimonio (fotogrametría). Actualmente, cursa estudios de Maestría en Gestión Cultural de la Universidad de Piura. 
devenir Vol. 7, N¹4, JULIO-DICIEMBRE 2020, PP. 107-130 - EstudIOS | ISSN 2312-7562 | E-ISSN 2616-4949

UNIVERSIDAD NACIONAL DE INGENIERÍ, LIMA

doi: https://doi.org/10.21754/devenir.v7i14.774

\section{Introducción:}

Para la elaboración de la presente investigación, se ha realizado el análisis de los diversos espacios del edificio de la Facultad de Arquitectura, Urbanismo y Artes de la Universidad Nacional de Ingeniería (FAUA-UNI). De esta manera se ha evaluado el conjunto arquitectónico y la relevancia de los elementos arquitectónicos que componen cada área para poder proyectar y definir los lugares específicos donde se realizarían las calas estratigráficas, ya que las mismas deben ser representativas para que la proyección cromática se extienda al conjunto arquitectónico. Una vez realizadas las calas estratigráficas en los puntos seleccionados, se procede a la interpretación cromática e identificación comparativa con las cartas de color estandarizadas, de esta manera se podrá identificar cada estrato cromático con un color específico y definir qué tonos son predominantes en cada cala. Además del análisis cromático, las calas brindarán información relevante sobre los distintos usos cromáticos en la historia de la FAUA.

El objetivo del trabajo consistió en determinar los diversos momentos cromáticos que fueron parte del edificio de la Facultad de Arquitectura, Urbanismo y Artes. Pues cada uno de los estratos de color identificados puede dar cuenta de un estilo e identidad que va de la mano a una época y contexto temporal. Es importante también, tomar conocimiento sobre las técnicas de preparación del muro, y de esta manera poder establecer una correlación que permita comprender los cambios sucedidos a lo largo del tiempo tanto a nivel cromático como en lo que se refiere a las técnicas de aplicación del material pictórico.

Según (Barros, 2010) "Las secciones y los diagramas estratigráficos son dos recursos gráficos que permiten, en el primer caso, mostrar las relaciones entre estratos a lo largo de un corte efectuado en la estructura y, en el segundo, ofrecer una visión del conjunto de relaciones entre todas las unidades estratigráficas (estratos y pérdidas)". Esto quiere decir que más allá de una información sobre acabados estéticos se va a contar con datos fehacientes sobre el comportamiento y estado de conservación de cada capa.

De acuerdo con la Carta del Restauro, se inserta el concepto del estudio estratigráfico aplicado como método de reconocimiento de las diversas capas aplicadas a la conservación de pintura y escultura."(...) Después de haber obtenido las fotografías, deberán realizarse catas mínimas, en puntos que no sean vitales para la obra, que abarquen todos los estratos hasta el soporte, y así quedarán determinadas las secciones estratigráficas, siempre que existan superposiciones, y podrá determinarse también el estado de la preparación". Sin embargo, este método de identificación puede ser extrapolado al estudio cromático de bienes inmuebles en proporción al área de estudio ya que, del mismo modo, permite realizar el análisis de las diversas capas que revisten el muro. (Carta del Restauro, 1972).

\section{El papel del color en la arquitectura}

El color en la arquitectura cumple un rol primordial dentro del concepto del espacio. No solo representa un aspecto estético, sino que configura la percepción del espectador frente al edificio.

El color puede afectar tanto en la concepción visual como espacial, por lo que podría condicionar al usuario del edificio al causarle distintas sensaciones. Por ello, la selección de los colores en un inmueble tiene una explicación y se apoya en la psicología del color y los valores cromáticos para reforzar ciertas sensaciones y estímulos en las personas.

El color va íntimamente ligado al diseño arquitectónico, tanto el cromatismo como la escala y temperatura tonal deben ser cuidadosamente aplicados de manera que permita interactuar con la luz de manera efectiva. 
Según (Muñoz, 2008), la función del color no solo tiene un fin estético, aunque ciertamente sea el más resaltante sino también el color tiene una función práctica, de resaltar las formas, enfriar o calentar los espacios en el caso de interiores dada la absorción de los rayos solares, sino también su función de acuerdo con el simbolismo cromático que puede generar en distintos espacios. Por otro lado, el uso del color en la arquitectura en paramentos externos, debe guardar estrecha relación con el entorno y corresponde tomar en cuenta en el análisis cromático su relación con la luminiscencia, ya que mientras mayor sea la potencia de la luz que incide sobre un plano, se tiende a disolver la intensidad del color.

\section{Interpretación e identificación mediante el uso de cartas de color}

Es importante tomar en cuenta la interpretación cromática de los diferentes estratos de color que conciernen a los resultados de las calas estratigráficas.

Dentro de la industria de manufactura de pinturas hay diversas cartillas a las cuales se les da nombres comerciales a los distintos tipos de color que son producidos de acuerdo con la marca. Sin embargo, muchas veces los nombres coinciden en su nomenclatura comercial, aunque difieren en cuanto al aspecto visual, ya que las fórmulas empleadas son distintas a cada marca o patente.

Es por ello por lo que, al momento de hacer la interpretación de los diversos estratos de color, sea imperativo hacer uso de un sistema de contraste cromático estandarizado para evitar que los resultados varíen en función a una u otra cartilla.

Es por esta razón que uno de los sistemas de identificación estandarizado a nivel mundial cs el Pantone ${ }^{\circledast}$. Se trata de un sistema estandarizado de reproducción de color. Dichas cartas, han sido realizadas mediante el uso de tintas específicas y son reproducibles en cualquier parte del mundo. Según la información proporcionada por su página institucional web: "El lenguaje del color de Pantone ${ }^{\circledR}$ es aplicable a todos los sectores que trabajan con color: textil, belleza, diseño de interiores, arquitectónico e industrial, reuniendo más de 10000 estándares cromáticos en diversos materiales, incluidos los de impresión, tejidos, plásticos, pigmentos y recubrimientos". Esto quiere decir que dicha interpretación de colores es transferible a cualquier área que haga uso de estos recursos cromáticos. (Pantone, 2019)

De acuerdo con los métodos de lectura con las cartas de color Pantone ${ }^{\oplus}$, en las cartas de color existentes se puede tener el código de color en tricromía RGB (red, green, blue o rojo, verde y azul), lo cual facilita su reproducción exacta en cualquier soporte y medio ya que los valores establecidos son fijos.

El uso de cartas cromáticas estandarizadas facilita mucho el análisis y el poder obtener resultados de manera cuantitativa a través de los códigos cromáticos.

\section{El edificio de la Facultad de Arquitectura, Urbanismo y Artes de la Univer- sidad Nacional de Ingeniería}

El edificio de la Facultad de Arquitectura, Urbanismo y Artes se encuentra ubicado en el campus de la Universidad Nacional de Ingeniería, situada la avenida Túpac Amaru 210, en el distrito del Rímac al norte del centro histórico de la ciudad de Lima (ver figura 1). Fue construida en el año de 1951 en un terreno destinado expresamente para el funcionamiento de la Facultad de Arquitectura, Urbanismo y Artes en la Universidad Nacional de Ingeniería.

El arquitecto Mario Bianco cumplió un papel relevante como proyectista, así como también lo tuvo Fernando Belaúnde Terry, en ese entonces jefe del Departamento de Arquitectura de la Escuela Nacional de Ingeniería (DAENI), quien estuvo a cargo de la 
devenir Vol. 7, N¹4, JULIO - DICIEMBRE 2020, PP. 107-130 - EstudIOS I ISSN 2312-7562 | E-ISSN 2616-4949

UNIVERSIDAD NACIONAL DE INGENIERÍ, LIMA

doi: https://doi.org/10.21754/devenir.v7i14.774

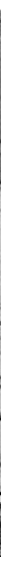

Figura 1. Vista aérea actual del edificio de la Facultad de Arquitectura, Urbanismo y Artes de la Universidad Nacional de Ingeniería. Elaboración propia sobre la base de Google Earth, 2019.

Figura 2 . Vista aérea de 1955 del edificio de la Facultad de Arquitectura, Urbanismo y Artes de la Universidad Nacional de Ingeniería. Departamento de Arquitectura de la Escuela $\mathrm{Na}-$ cional de Ingenieros (1955). El Arquitecto Peruano, 210-211, 23-37. gestión y de liderar el proyecto. Belaúnde es quien convoca a concurso entre los profesores, sin embargo, solo fueron presentados dos anteproyectos, el de Mario Bianco y el de Raúl Morey Menacho, ganando el primero por unanimidad. Existieron también cambios fundamentales introducidos en el proyecto final. Uno era la introducción de un tercer eje compositivo con la finalidad de marcar los ingresos, los mismos que no estaban tan marcados en el anteproyecto, otro cambio correspondería a la definición magistral de la estructura, plegando el techo del auditorio, así como los muros del cerramiento y finalmente, dotar de mayor dinamismo y tensión en la relación de los volúmenes y soporte estático. (Beingolea, 2010)

Según López, en octubre del año de 1955, se inauguran los edificios de la Facultad de Arquitectura, juntamente con los de Ingeniería Civil, Ingeniería Química e Industrial e Ingeniería Mecánica y Electricidad. (López Soria, 2017 , p. 95)

De acuerdo con la descripción realizada por Aldo Facho (2008), la facultad de estilo moderno se construye en una planta en "T", donde el brazo horizontal serían las aulas-talleres y el brazo vertical lo constituye el hall principal en planta baja y la biblioteca en la planta superior. Del mismo modo se aprecia una construcción de menor relevancia que flanquea la entrada a la facultad donde funcionan oficinas y aulas complementarias. El auditorio y la sala de artes se trabajan como volúmenes libres, el primero rematando el eje transversal del acceso y la segunda como una rotonda libre en uno de los patios. El patio hundido es una obra posterior, así como la cafetería y el centro de estudiantes (semisótano). (Facho, 2008) (ver figura 2)

\section{Metodología de elaboración de calas estratigráficas:}

Para realizar la prospección cromática en los muros correspondientes al edificio de la Facultad de Arquitectura, Urbanismo y Artes de la UNI, se procedió a realizar lo siguiente:

\section{Identificación del espacio y designación de las áreas donde se elaborarán las estratigrafías}

Para la identificación de los lugares estratégicos de la elaboración de las calas se ha procedido a realizar el reconocimiento de las áreas y relacionando los espacios en función a su uso y tipología constructiva (ver Figuras 3 y 4).

Los espacios se analizan y se aprecian en conjunto, por lo que muchas veces la paleta cromática suele seguir patrones específicos que permiten dilucidar el color en toda la 


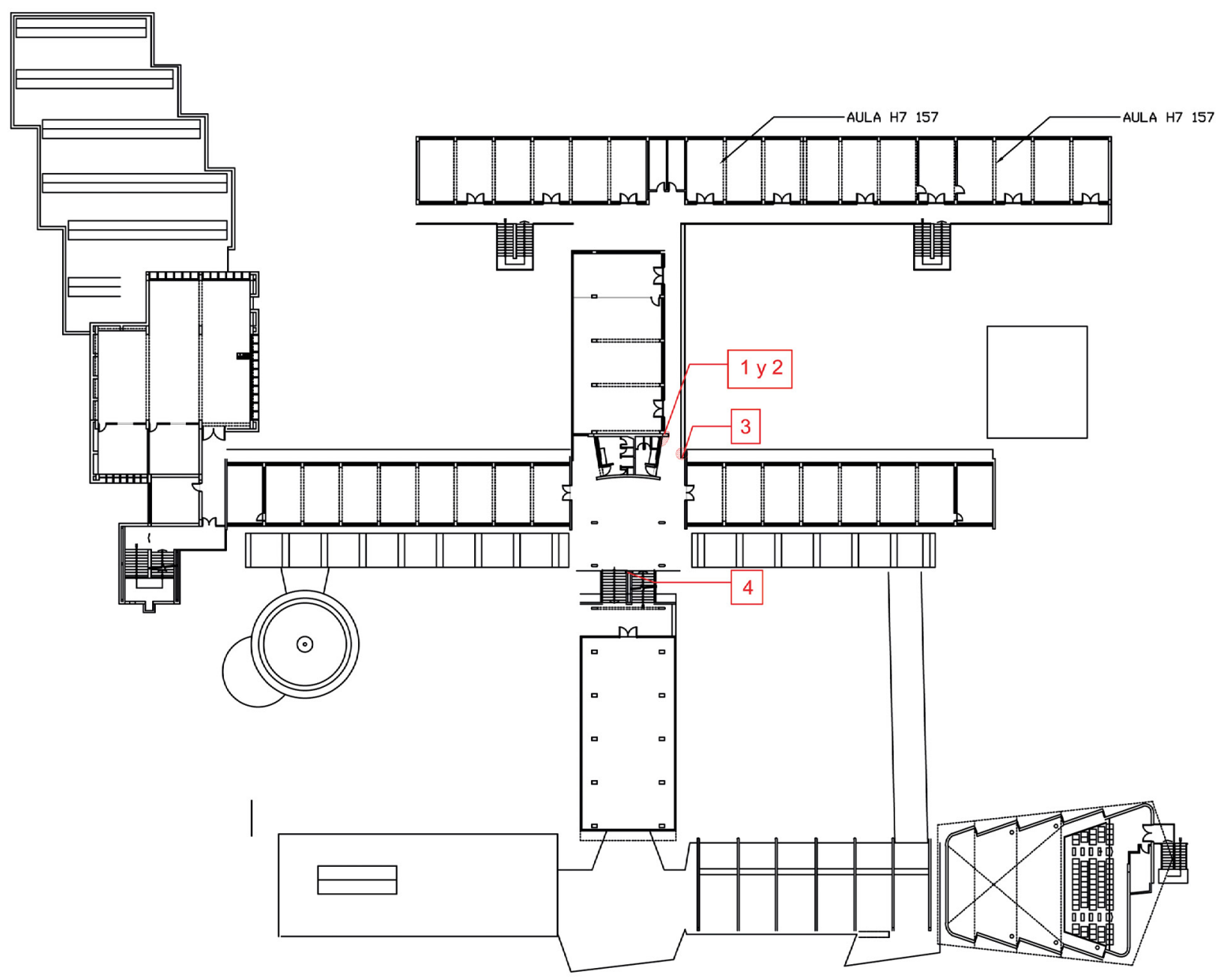

SEGUNDA PLANTA

Figura 3. Ubicación de calas estratigráficas Nro. 1 - 4. Elaboración propia en base a los planos actualizados provistos por la FAUA para la consultoría de estudio de color del edificio de la FAUA-UNI, 2017.

extensión del área. La identificación de los espacios se ha dividido por zonas, por ello se han reconocido 13 zonas diferentes para realizar las prospecciones cromáticas (ver Figura 5).

\section{Delimitación de calas}

Una vez identificadas las áreas a muestrear, se procede a seleccionar los muros específicos sujetos a exploración cromática, estos van a depender de la importancia y extensión de estos en cuanto a área, y la repetición de elementos arquitectónicos que se pueden proyectar (como en el caso de las columnas). Básicamente se realizarán las siguientes acciones:

- Trazado de la cala con tiza: para ello se hace la medición de la cala con una regla y se marca las dimensiones con una tiza. Las medidas van entre 5 a $7 \mathrm{~cm}$. de ancho y $2 \mathrm{~cm}$. de alto por cada capa. 


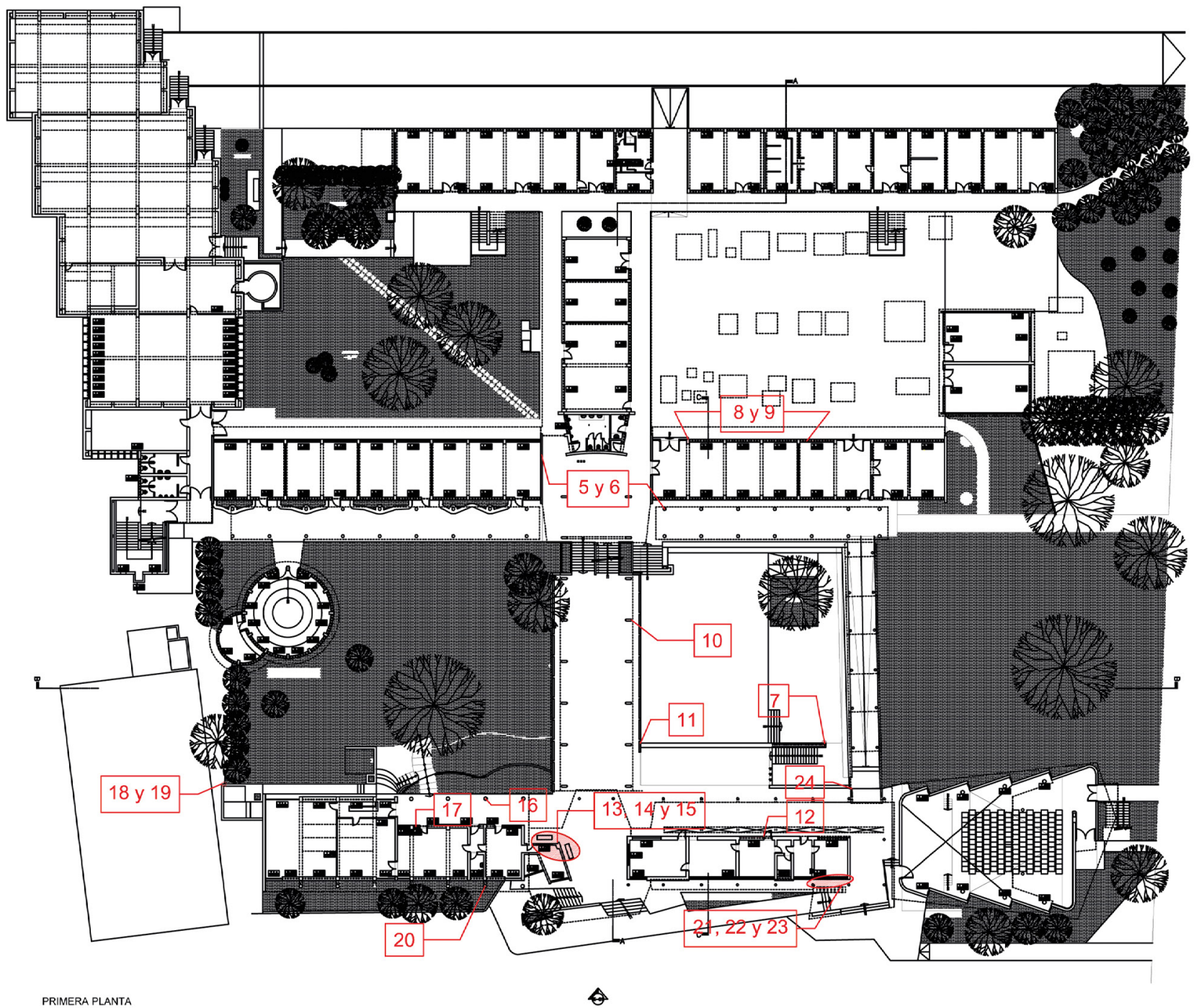

Figura 4. Ubicación de calas estratigráficas Nro. 5 - 24. Elaboración propia en base a los planos actualizados provistos por la FAUA para la consultoría de estudio de color de la facultad, 2017.

\section{Exploración cromática}

Se realiza el raspado de cada capa con un bisturí \#12 de hoja redondeada, por cada estrato hallado, siguiendo hacia abajo hasta llegar al soporte en caso se considere relevante para determinar la capa original.

La exploración cromática representa la prueba fehaciente de los colores que han formado parte de la historia cromática del inmueble. Por ello, en esta instancia es necesario realizar el registro fotográfico de la evidencia fidedigna del color. Del mismo modo, gracias a la exploración se podrá definir el estado de conservación de cada capa, así como el comportamiento físico de cada una de ellas a lo largo del tiempo.

\section{Registro fotográfico}

El registro fotográfico se realiza para poder plasmar visualmente la totalidad de las capas obtenidas al momento de realizar la exploración cromática. Este tipo de documentación es de suma importancia, porque gracias su carácter de representación de alta fidelidad, permitirá transmitir dicha información de cara a futuras investigaciones. 

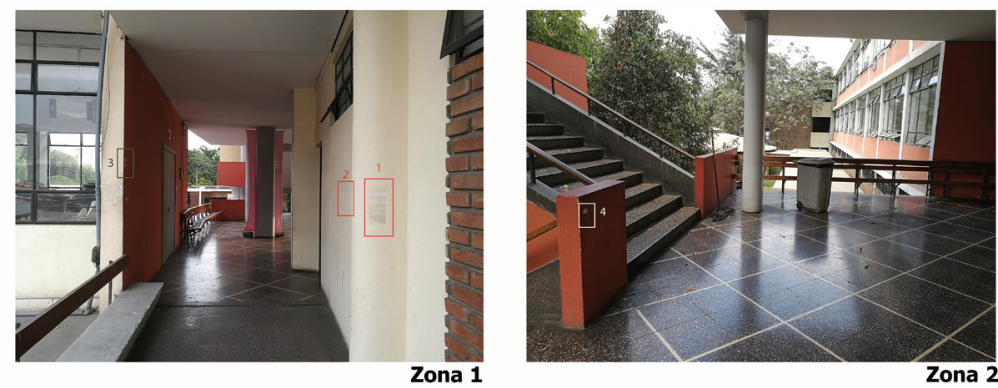

Zona 2
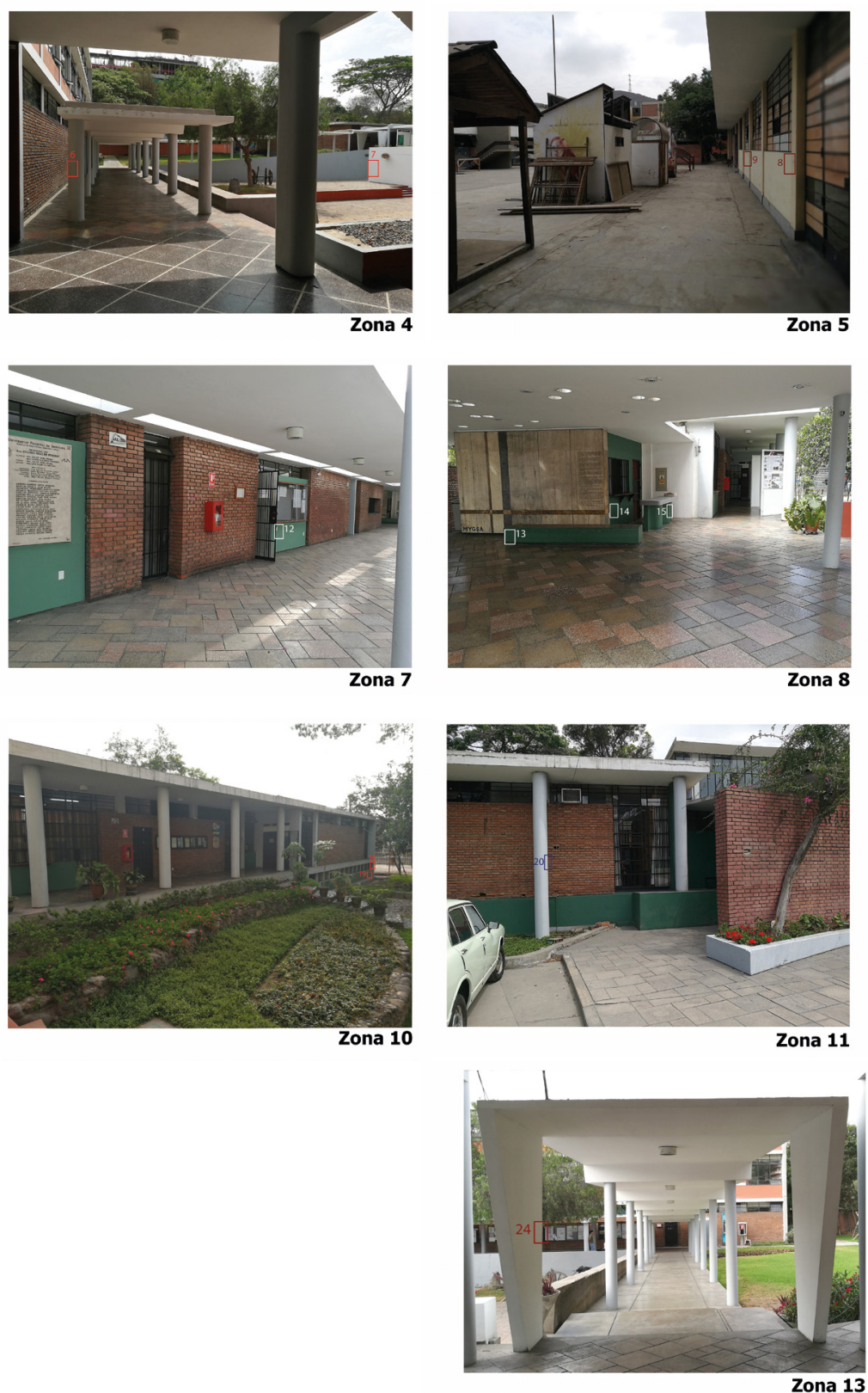
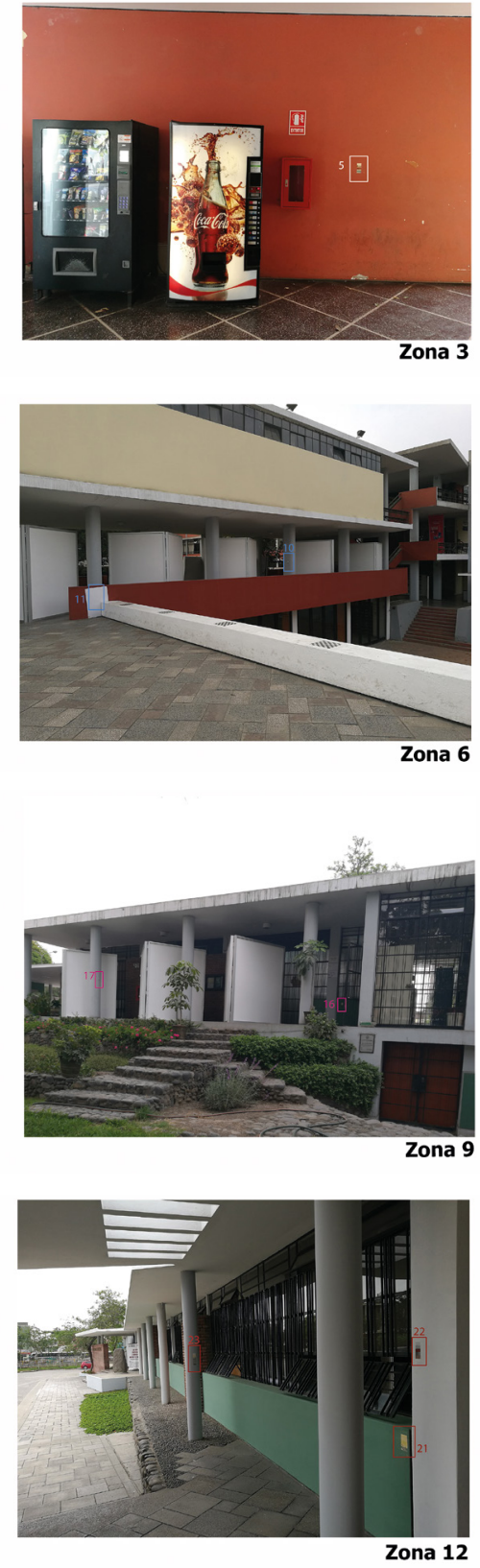

Figura 5. Zonas definidas en el edificio de la Facultad de Arquitectura, Urbanismo y Artes. Archivo fotográfico de la autora, 2017 

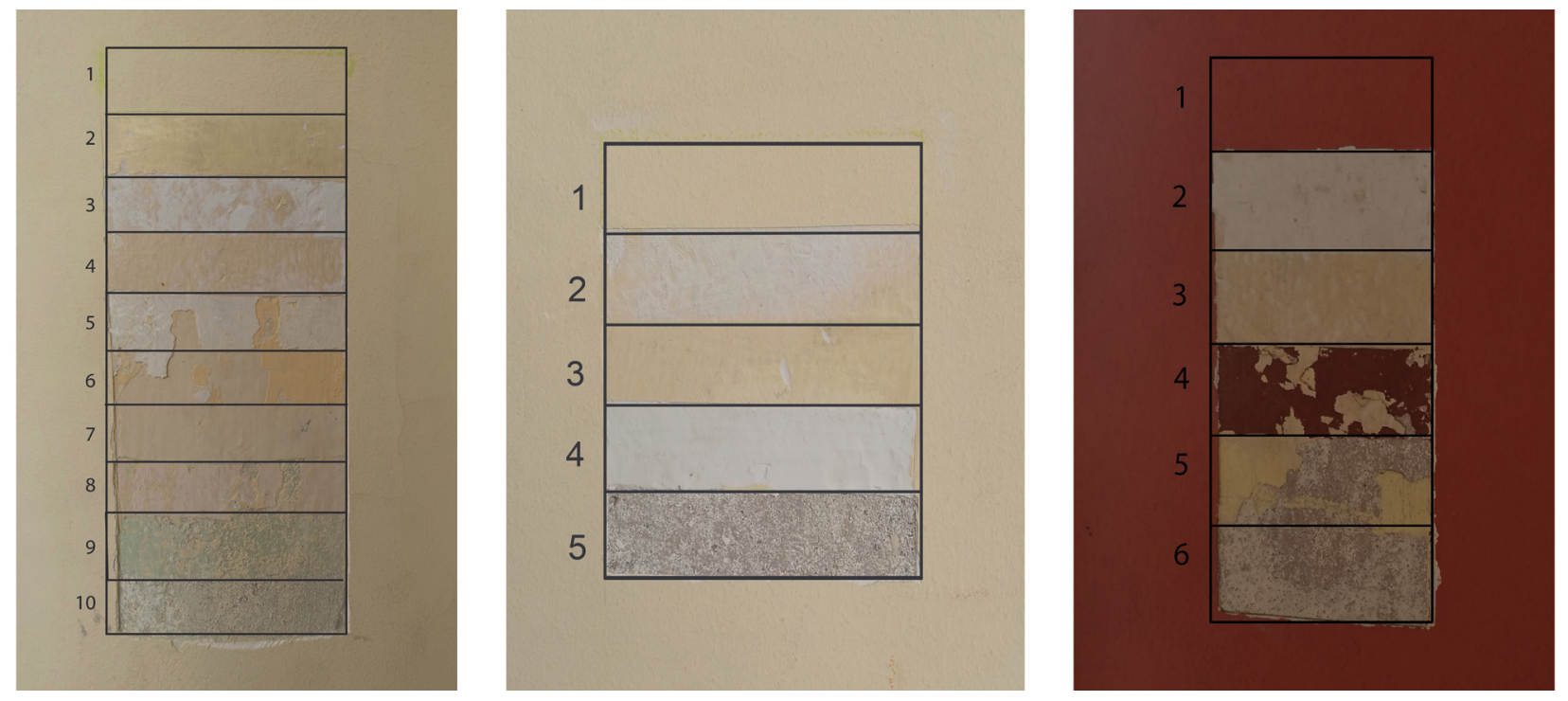

Figura 6. Calas estratigráficas № 1, 2 y 3. Archivo fotográfico de la autora, 2017.

Para el registro fotográfico se recomienda hacer uso de cámaras digitales que posean un mínimo de 10 megapíxeles de resolución y hacer uso de lentes que no distorsionen la perspectiva de la toma como los lentes zoom, teleobjetivos, lentes ojo de pez. Por lo tanto, se recomiendan lentes focales fijos de $50 \mathrm{~mm}$., para de esta manera, evitar cualquier distorsión en la toma.

\section{Interpretación de la información}

- Interpretación cromática: Consiste en analizar describir y comparar el número de estratos hallados y establecer su correspondencia cromática mediante el uso de cartas de color estandarizadas para poder identificar el color real y poder replicarlo

- Interpretación gráfica: Consiste en elaborar en un programa de diseño 3D, la representación tridimensional de la cala estratigráfica de cada una de las capas y de esta manera explicar la distribución consecutiva de cada uno de los estratos para su mejor comprensión.

\section{Evaluación de resultados}

La evaluación de resultados se ha realizado de forma individualizada por cada cala estratigráfica, por ello, cada una de ellas tiene una interpretación propia en cuanto a los diferentes tiempos cromáticos y el comportamiento de cada capa según su estado al momento de realizar las calas.

\section{Zona 1: Patio posterior, segundo piso del edificio de la FAUA-UNI - Columna y pared}

\section{- Cala estratigráfica Nro. 1}

Ubicación: Segundo piso del patio posterior del edificio de la FAUA-UNI, sobre una columna adosada semicircular.

Se ha encontrado 10 estratos, el último se refiere al cemento. Para realizar la interpretación cromática, se ha contado desde la capa más superficial hacia el soporte.

Respecto al comportamiento de los sustratos se puede inferir que la capa 3 es muy porosa y obedece a una capa de preparación superpuesta a otro color. Por otro lado, la 
capa 5, se observa inestable, la misma no tiene adherencia sobre la capa subyacente. Lo mismo se observa en la capa 6 y en la capa 8. Finalmente, el estrato 9 se presenta muy delgado y pulverulento.

La capa 6 también es un sustrato inestable que, de acuerdo con la cala, tiende a desprenderse con facilidad. La capa correspondiente a lo que se entiende como el color original, de color verde, se dispone directamente sobre el cemento y no cuenta con una capa de preparación del muro.

La gama de colores en un principio, tornaron del verde a tonalidades más claras, para finalmente optar por colores amarillos claros más luminosos.

\section{- $\quad$ Cala estratigráfica Nro. 2:}

Ubicación: realizada sobre un muro adyacente a la columna adosada semicircular.

Presenta 5 capas, 2 de las cuales, el estrato 2 y el 4 corresponden a bases de preparación del muro. Los colores que se han encontrado (solo 2 estratos) se encuentran dentro de la misma gama de color, amarillos cálidos y su estabilidad es buena. Las bases de preparación halladas son de consistencia porosa: la capa 2 es delgada y se encuentra sobre una de las capas de color, mientras que la capa de preparación de la capa 4, es de un grosor medio y descansa directamente sobre el soporte del muro. (Ver figura 6)

\section{- Cala estratigráfica Nro. 3}

Ubicación: Se ha realizado en el muro lateral del segundo piso.

Presenta 6 capas, 4 de las cuales están referidas a estratos de color, una capa de preparación tardía evidenciada en la capa Nro. 2 y la capa Nro. 6 de soporte del muro (cemento)

En cuanto al análisis cromático, se observan dos momentos muy saltantes que corresponden a las tonalidades cálidas luminosas (amarillos claros) y los tonos rojos.

Por otro lado, en lo que se refiere a la evaluación de las capas se puede inferir que la capa 4 y la capa 5 no se encuentran estables. Por un lado, se observa que la capa 4 se desprende con facilidad y no presenta buena adhesión al estrato subyacente, y la capa 5 se observa con múltiples faltantes y presenta escasa adherencia al soporte del muro. Del mismo modo, sobre el cemento se evidencia una ligera preparación blanca que no se ha hallado propiamente como una capa, sino como un vestigio pulverulento. Se puede inferir que esta, en un primer momento, fungió como base de preparación de la pared.

\section{Zona 2: Escalera del Hall}

- Cala estratigráfica Nro. 4

Ubicación: Realizada sobre el muro bajo de las escaleras que bajan al Hall central

Esta cala presenta 6 estratos. La capa 4 y la capa 5 se encuentran medianamente estables. La capa más antigua es en extremos delgada y se encuentra dispuesta directamente sobre el soporte de cemento.

En cuanto a la interpretación cromática de esta cala, podemos observar que en el tiempo se han dado cambios bruscos de color. En un inicio se aprecia un alto predominio de los colores rojizos, sin embargo, en la capa Nro. 3 se observa un salto de color bastante notorio, porque se torna hacia los tonos amarillos claro y marfiles, para posteriormente, volver a la tonalidad rojiza, muy similar al sustrato original. (ver Figura 7)

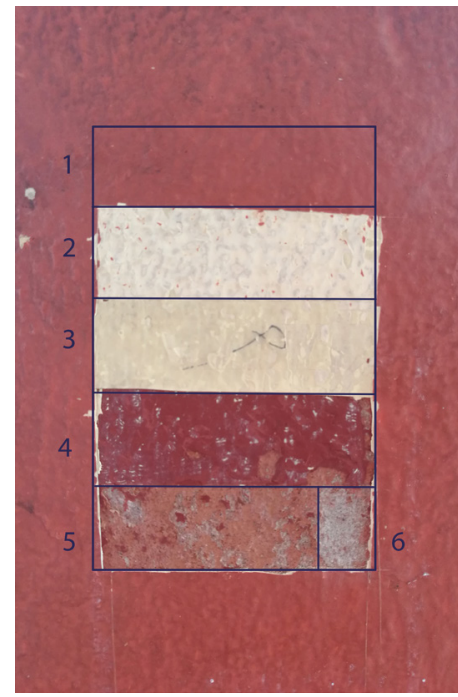

Figura 7. Calas estratigráficas № 4. Archivo fotográfico de la autora, 2017.

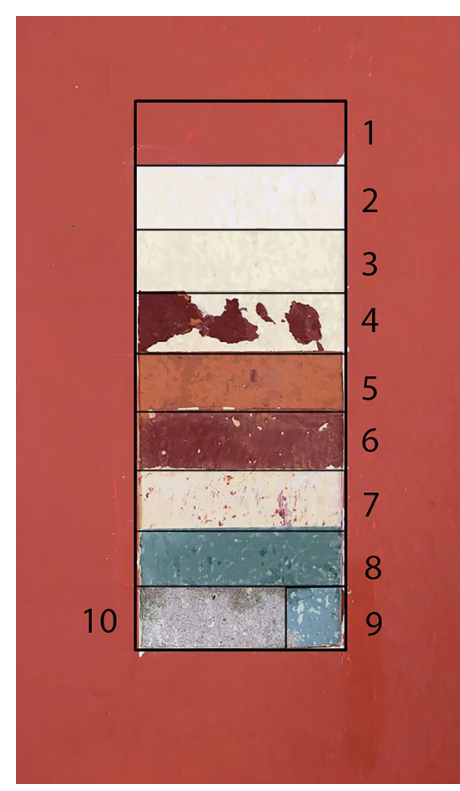

Figura 8. Calas estratigráficas $\mathrm{N}^{\circ} 5$. Archivo fotográfico de la autora, 2017. 
devenir Vol. 7, N¹4, JULIO- DICIEMBRE 2020, PP. 107-130 - EstUDIOS | ISSN 2312-7562 | E-ISSN 2616-4949

UNIVERSIDAD NACIONAL DE INGEEIERÍA, LIMA

doi: https://doi.org/10.21754/devenir.v7i14.774

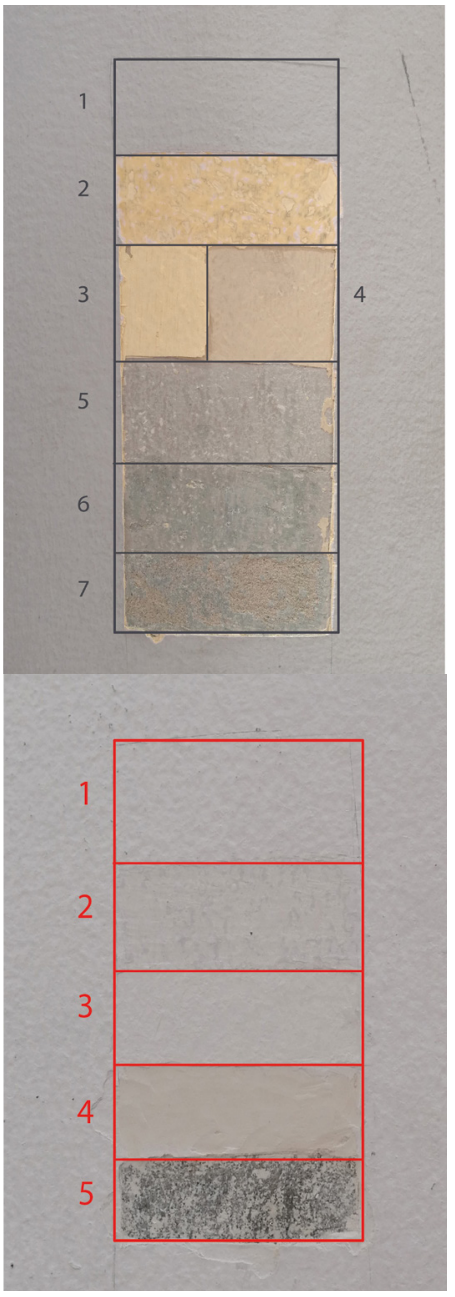

Figura 9. Calas estratigráficas № 6 y 7. Archivo fotográfico de la autora, 2017.

\section{Zona 3: Hall de acceso al patio posterior}

- Cala estratigráfica Nro. 5

Ubicación: pared lateral noroeste.

En la presente muestra se han hallado 10 estratos: 9 de ellos corresponden a colores y el último al soporte de la pared (cemento).

En cuanto al análisis cromático, en esta cala se observan continuos cambios de color. En un inicio se observa un predominio de los colores fríos como los tonos azulados y verdosos, para luego virar a un color claro y luminoso. Posteriormente predominan los colores rojizos, retornando a una coloración clara para finalmente recuperar una tonalidad rojiza de las capas subyacentes ( $N \circ 4,5$ y 6 ).

En el estrato Nro. 4 se observa un color rojo teja intenso, el cual no es muy estable y solo se han podido recuperar fragmentos de este. A diferencia del anterior el estrato 6 se encuentra muy bien adherido a la capa subyacente. Finalmente podemos concluir que el color original (verde azulado) se dispone directamente sobre el soporte de cemento. (ver Figura 8)

\section{Zona 4: Columna circular y patio hundido}

- Cala estratigráfica Nro. 6

Ubicación: Fuste de columna circular adyacente al patio hundido

Esta muestra presenta 7 capas, 6 de las cuales pertenecen a momentos pictóricos del muro y la capa 7 constituye el soporte.

En lo referente a la interpretación cromática, en esta cala se observa 6 estratos de color y no se aprecia capa de preparación del muro. Los colores predominantes son los amarillos claros, aunque no son colores que puedan ser considerados originales. Se aprecia que este tipo de elementos arquitectónicos ha tenido un cambio de color importante que va de las tonalidades grises hacia los amarillos, para volver en su último y más reciente momento pictórico hacia las tonalidades grises.

El estrato Nro. 3 corresponde a un color amarillo cálido el mismo que se encuentra desprendido del sustrato subyacente y es muy sensible al raspado. En este caso los colores más estables a nivel de materia están referidos a las capas más antiguas (capa Nro. 5 y 6). (ver Figura 9)

\section{- Cala estratigráfica Nro. 7}

Ubicación: Muro de patio hundido

Esta cala presentó 5 capas, tres de las cuales conciernen a estratos de color, otra evidencia una base de preparación de consistencia gruesa (capa 4) y el estrato 5 corresponde al soporte del muro (cemento).

En esta cala, predominan los colores blancos y no se aprecian saltos cromáticos en ninguno de los momentos hallados. Todas las capas son estables y presentan buena adherencia al estrato subyacente; además de evidenciarse una capa de preparación del muro de consistencia gruesa. (Ver figura 9)

\section{Zona 5: Aulas de patio posterior}

- Cala estratigráfica Nro. 8

Ubicación: pilastra adosada de patio posterior 

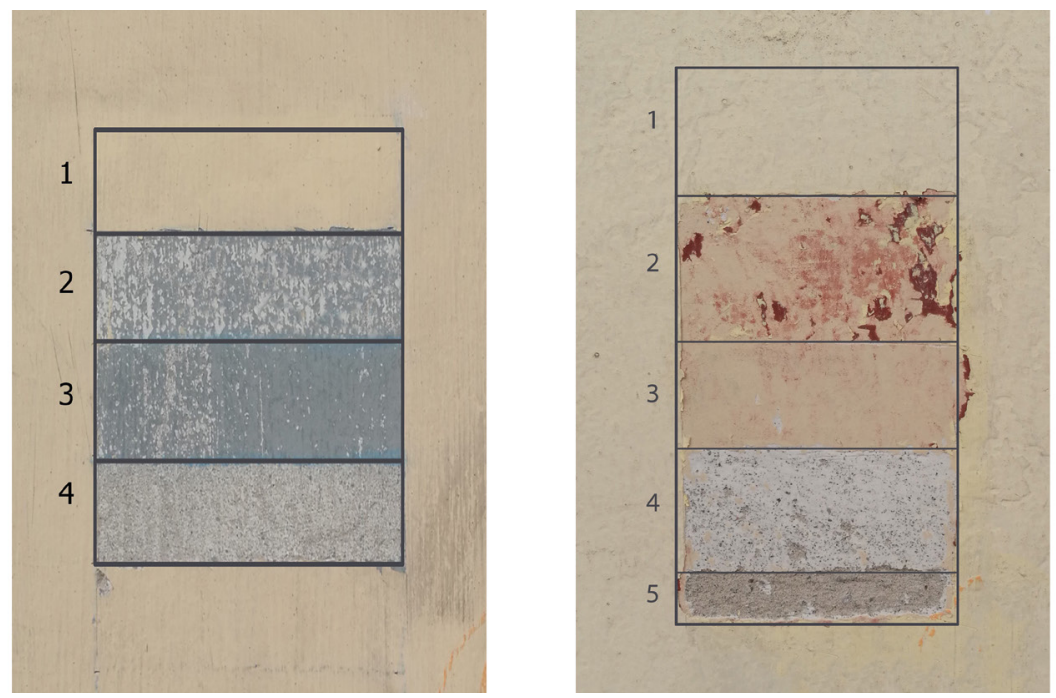

Figura 10. Calas estratigráficas № 8 y 9. Archivo fotográfico de la autora, 2017.

En esta cala sólo se han evidenciado 4 estratos, 3 corresponden a colores y la cuarta se identifica como el cemento o soporte.

En cuanto al análisis cromático se establece que los colores predominantes son los tonos grises fríos y en el último estrato se produce un cambio radical de color, pasando a un tono cálido y luminoso.

El análisis de la estabilidad de los estratos indica que las tres capas de color existentes se encuentran firmes y estables con buena adhesión entre ellas. Sin embargo, no se aprecia capa de preparación del muro. (Ver figura 10)

- Cala estratigráfica Nro. 9

Ubicación: muro bajo del patio posterior

En la presente cala se observan 5 capas diferentes, la segunda capa que correspondería a un rojo, se encuentra muy inestable, solo se hallaron restos puntuales y presentaban falta de adherencia a la capa subyacente, se tiene la hipótesis que haya sido parcialmente retirada o lijada en una etapa anterior. En este caso, si se ha evidenciado la presencia de capa de preparación del muro.

En lo que respecta a la interpretación del conjunto cromático, se observa que los colores predominantes son los claros cálidos. Además, se aprecia un cambio de color muy resaltante entre la capa 3 y la capa 2, para luego, retomar la tonalidad cromática del estrato original (ver Figura 10).

\section{Zona 6: Hall central}

\section{- Cala estratigráfica Nro. 10}

Ubicación: Fuste plano de columna

En la presente cala se han encontrado 8 estratos: 7 de ellos corresponden a colores y el octavo atañe al soporte de la pared (cemento). En este caso todos los estratos se encuentran estables y presentan buena adherencia a la capa subyacente. Tal y como se ve en otras prospecciones cromáticas, no se observa evidencia de capa de preparación del muro. 


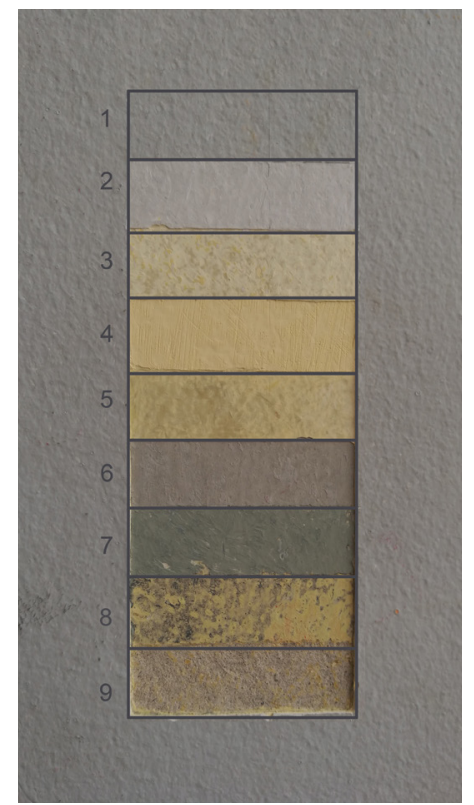

Figura 11. Calas estratigráficas № 10. Archivo fotográfico de la autora, 2017.

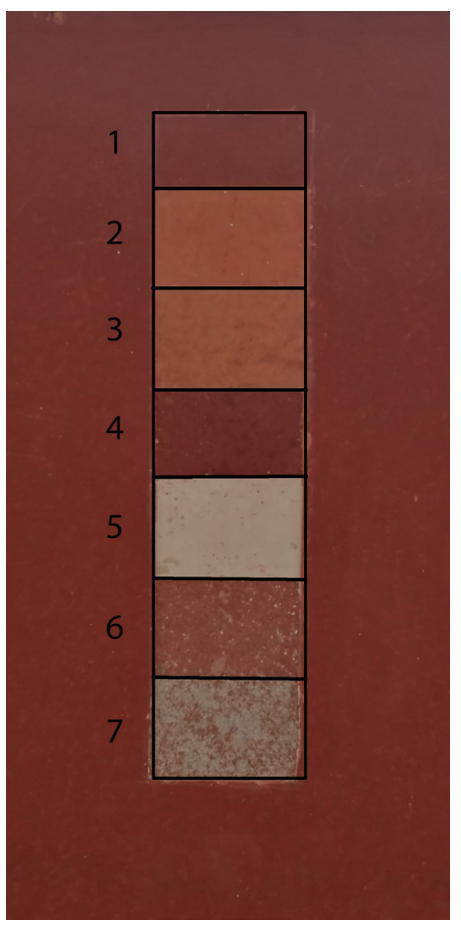

Figura 12. Calas estratigráficas № 11. Archivo fotográfico de la autora, 2017.
En lo que respecta al análisis cromático, existe una marcada predominancia del color amarillo que desde un comienzo se presenta como el color original (capa 8) para luego pasar a una tonalidad verde, (capa 7), retomar las tonalidades luminosas amarillas y volver a los colores grises que se encontraron hasta la elaboración del presente estudio. (ver Figura 11)

- Cala estratigráfica Nro. 11

Ubicación: Muro bajo del hall central

En la presente cala se han encontrado 7 capas, 6 de ellas corresponden a colores y el último, al soporte del muro (cemento).

Se ha observado que todas las capas halladas se encuentran en buen estado de conservación y presentan estabilidad y adherencia a las capas subyacentes. Al igual que en casos anteriores no se evidencia la presencia de base de preparación entre el estrato original y el soporte.

En cuanto a la interpretación cromática, se observa la predominancia de los colores rojizos, a excepción de un salto cromático saltante entre la capa 6 y la capa 5 donde se vira a un color blanco de matiz cálido y en momentos posteriores, retomar a las tonalidades rojizas hasta la última capa encontrada que se refiere a una capa actual. (Ver figura 12)

\section{Zona 7: Zona administrativa}

En esta zona se realizó una cala en uno de los muros bajos de la oficina de calidad académica (área administrativa)

- Cala estratigráfica Nro. 12

Ubicación: muro bajo de oficina

En esta cala se hallaron 6 capas de las cuales 5 corresponden a colores y 1 a soporte de muro (cemento). En lo que respecta al análisis cromático, los colores predominantes son los colores cálidos y luminosos, los mismos que difieren de la capa original (Estrato 5) de color amarillo intenso. Posteriormente, a partir de la capa 2 se aprecian dos saltos cromáticos importante, uno que vira al gris y otro al verde oscuro. En lo que se refiere a estabilidad de los estratos, se ha encontrado que la capa 2 es muy delgada, sin embargo, presenta buena adherencia a la capa subyacente. Por otro lado, la capa original se encuentra dispuesta directamente sobre el soporte sin contar con capa de preparación. (Ver figura 13)

\section{Zona 8: Lateral izquierda}

En esta zona se observan tres elementos distintos pintados hasta el momento del presente estudio (banqueta, mesa de concreto y muro), del mismo color, lo cual podría indicar que es el mismo tono el que se extiende de forma homogénea a dichos elementos. Pero al tratarse de estructuras diferentes, se procedió a realizar una prospección cromática por cada uno de estos.

- Cala estratigráfica 13

Ubicación: banqueta

En esta cala se hallaron 4 estratos distintos, 3 de los cuales corresponden a superficies cromáticas y la capa 4 está referida al soporte del muro (cemento) 
De acuerdo con el análisis cromático se puede inferir que la capa Nro. 3 (color negro), atañe a la capa original y las capas 1 y 2 están identificadas como momentos posteriores. En este caso, el color predominante de la cala comprende las tonalidades verdes. Sin embargo, entre la capa 3 y la capa 2 se aprecia un salto cromático muy resaltante que obedece a un cambio de estilo.

En cuanto a estabilidad de las capas, el estrato 1 y 2 se encuentran firmes y presentan buena adhesión a las capas subyacentes. La capa 3 (pintura original) se aprecia muy delgada e inestable y se encuentra dispuesta directamente sobre el cemento, es decir que el muro no cuenta con capa de preparación.

\section{- Cala estratigráfica 14}

Ubicación: muro inferior

En la presente cala se ha encontrado 4 estratos, tres de los cuales corresponden a momentos pictóricos y la capa 4 al soporte (cemento).

En este caso, no se aprecia un color predominante. Las tres capas son completamente distintas entre sí. La capa 3 que se interpreta como la original, es de rojo intenso, posteriormente se observa una capa de color blanco y el momento actual se encuentra pintado en un color verde.

A nivel estructural las capas 1 y 2 cuentan con estabilidad y buena adherencia a los estratos subyacentes, sin embargo, la capa original (capa 3) se encuentra directamente sobre la superficie de cemento y se desprende con relativa facilidad del soporte en algunas zonas, mientras que en otras se encuentra fuertemente adherida. (Ver figura 14)

- Cala estratigráfica Nro. 15

Ubicación: Mesa de concreto de base ondeada

En la presente cala se ha encontrado 5 capas, 4 de ellas corresponden a capas de color y la última (capa 5), al soporte (cemento).

De acuerdo con el análisis cromático, se puede observar que los colores predominantes son los verdes. No obstante, el estrato original (capa 4) está definido por un tono gris. Posterior a esta capa se encuentra un estrato de tonalidad negra, para luego superponerse a esta las dos capas de colores verdes.

A nivel estructural la mayoría de las capas se encuentran estables, a diferencia del segundo momento pictórico que pone en evidencia que la capa negra presenta múltiples desprendimientos y mala adherencia a la capa original.

Al igual que en muchos casos vistos anteriormente, la capa original se dispone directamente sobre el soporte de cemento. (Ver figura 14)

\section{Zona 9: Bloque lateral adyacente al jardín}

- Cala estratigráfica Nro. 16

Ubicación: Muro bajo de la Sala de profesores

En esta cala se ha hallado 6 estratos, 5 de ellos corresponden a capas de color, mientras que la última capa (Nro. 6) al soporte de cemento.

Según la interpretación cromática, se pude ver que los colores predominantes son los amarillos (amarillos cálidos apastelados y el amarillo cadmio). Posteriormente a partir de la capa 2 se produce un cambio cromático significativo, donde se deja atrás los

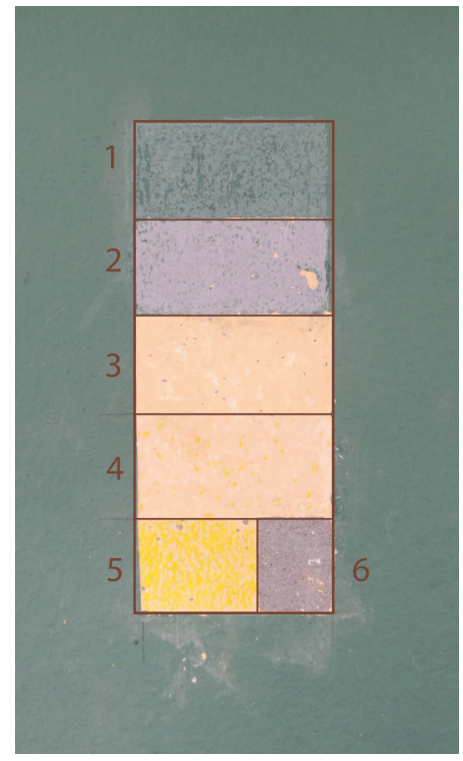

Figura 13. Calas estratigráficas № 12. Archivo fotográfico de la autora, 2017. 


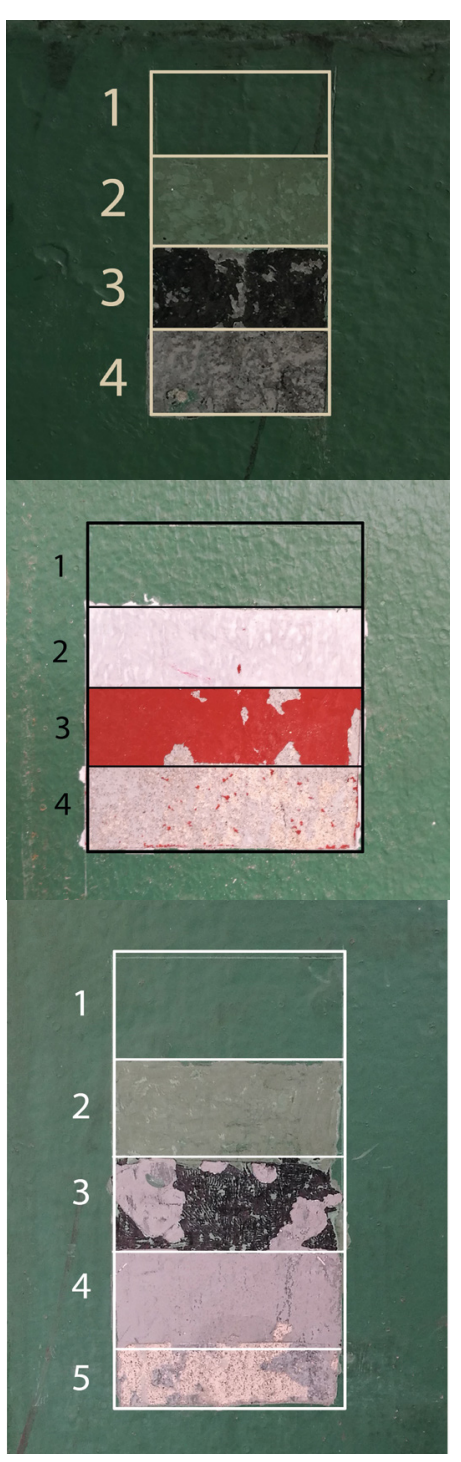

Figura 14. De arriba hacia abajo calas estratigráficas $\mathrm{N}^{\circ} 13,14$ y 15 respectivamente. Archivo fotográfico de la autora, 2017. tonos luminosos para pasar a un color gris (capa 2) y posteriormente el verde que se considera como la capa actual hasta el momento del presente estudio.

Por otro lado, según el análisis del material se puede inferir que la capa 2 es una capa delgada que, si bien tiene una adherencia aceptable a la capa subyacente, tiende a desprenderse en zonas puntuales al momento de realizar el proceso de raspado. Lo mismo pasa con la capa 5, la misma que mantiene cierta estabilidad a pesar de que no se ha hallado evidencia de la presencia de una capa de preparación del muro. (Ver figura 15)

- Cala estratigráfica Nro. 17.

Ubicación: Fuste de columna circular

En la presente capa se ha encontrado 7 estrados donde 5 de los cuales corresponden a capas bien distinguidas entre sí, mientras que la 6 se halla un vestigio muy fino de una coloración amarilla y finalmente la capa 7 que se encuentra identificada como el soporte (cemento).

En lo que se refiere al análisis cromático, los colores predominantes hallados son los amarillos claros. El vestigio de la primera capa de color amarillo cambia a un segundo momento hacia un tono verdoso para posteriormente, virar a un gris cálido y posteriormente retomar las tonalidades originales de amarillos apastelados y nuevamente en la última capa, optar por un gris claro (capa 1).

De acuerdo con el análisis de las capas, se observa que la capa Nro. 3 no presenta buena adhesión a la capa subyacente, además la capa 5 es delgada, la misma que se superpone a la capa 6 de color amarillo claro. En efecto, la capa original se observa en extremo pulverulenta y delgada. Se tiene la hipótesis que esta capa en un momento pudo ser lijada para favorecer la adherencia de la capa posterior al momento de pintar nuevamente dicha columna. )

\section{Zona 10: Depósito lateral adyacente al jardín}

- Cala estratigráfica Nro. 18

Ubicación: Ventana de almacén (sótano)

La cala presenta 6 estratos, 5 de los cuales corresponden a capas de color y la capa Nro. 6 , al soporte del muro.

En lo que compete al análisis cromático, se ha observado que los estratos se encuentran estables. Los colores predominantes en esta cala pueden identificarse en la gama de colores claros (blancos), teniendo ligeras variaciones en cuanto a matices y temperatura cromática.

En lo referente al análisis de las capas se puede ver que la capa original (capa 5) se encuentra directamente sobre soporte del muro (cemento). (Ver figura 16)

- Cala estratigráfica Nro. 19

Ubicación: muro bajo

En esta cala se ha encontrado 4 capas, donde tres de las cuales están referidas a estratos de color y la última, al soporte del muro (cemento).

Mediante el análisis cromático se puede inferir que los colores predominantes se encuentran en la gama de los grises, para posteriormente pasar a un color más fuerte y llamativo como el verde.) 
En cuanto al análisis material, se observa que las capas 2 y 3, no muestran buena adherencia y se desprenden con facilidad. Al igual que en casos anteriores, el color original se encuentra en contacto directo con el soporte, es decir, no hay vestigios o evidencias de capa de preparación.

\section{Zona 11: Entrada a la facultad (lado este)}

- Cala estratigráfica Nro. 20

Ubicación: Fuste de columna circular

Presenta 7 capas, 6 de las cuales se definen como estratos de color y la última referida al soporte del muro (cemento)

En lo referente al análisis cromático, se observa que existe una marcada predominancia hacia los colores grises. Sin embargo, el color original corresponde a un amarillo cadmio. Posteriormente ocurre un importante cambio en cuanto al color, ya que la siguiente capa vira hacia un gris frío. Dicha tendencia a los grises se mantiene desde la capa 5 hasta la capa 3, para luego retomar un tono amarillo claro y finalmente, en la capa actual, vuelve a un tono gris luminoso.

En cuanto al análisis del material se observa que todas las capas son estables y mantienen buena adherencia. En el caso de la capa 5 se ha podido evidenciar que se trata de un estrato de consistencia dura, fuertemente adherida al original. Finalmente, la capa original, está dispuesta directamente sobre el soporte (cemento). (Ver figura 17)

\section{Zona 12: Entrada lateral lado oeste de la facultad}

En esta zona se ha realizado 3 calas en el muro bajo, la columna y el fuste de una columna circular

\section{- Cala estratigráfica Nro. 21}

Ubicación: Muro bajo

En la presente cala se ha hallado 7 estratos, 6 de los cuales están identificados como capas de color y la última, corresponde al soporte del muro (cemento).

En cuanto al análisis cromático, se ha podido determinar la preponderancia de los colores amarillos cálidos luminosos. Sin embargo, la capa original está definida por color verde, para posteriormente pasar a las tonalidades amarrillas desde la capa 5 hasta la capa 2, donde finalmente se retoma el color verde que guarda similitud con el original hallado.

Según el análisis de material, se ha observado que desde la capa 5 hasta la 1 existe buena adherencia de la pintura. Sin embargo, la capa original, presenta problemas de adhesión y cohesión, esto sumado a que se encuentra directamente sobre el soporte de cemento.

\section{- Cala estratigráfica Nro. 22}

Ubicación: Columna del muro

En esta cala se ha hallado 7 estratos, de los cuales 6 de ellos se refieren a capas de color y la última capa corresponde al soporte (cemento)

De acuerdo con el análisis cromático: se ha podido evidenciar el predominio de los colores grises, que al pasar el tiempo se han ido aclarando hasta llegar a la capa actual de coloración blanca. Sin embargo, el color original, corresponde a un gris medio el mismo que se encuentra directamente dispuesto sobre el soporte de cemento. Por

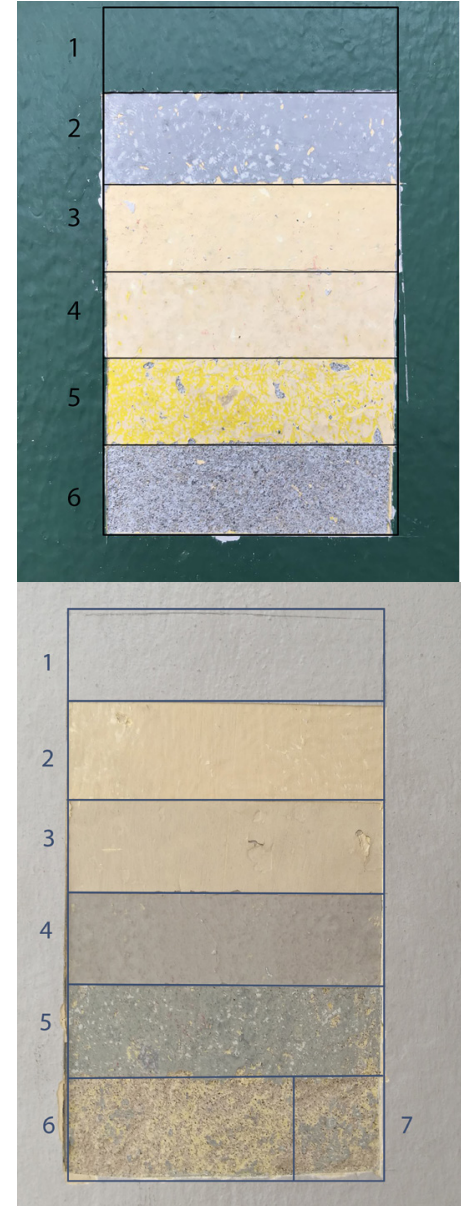

Figura 15. De arriba hacia abajo calas estratigráficas $\mathrm{N}^{\circ} 16$ y 17 respectivamente. Archivo fotográfico de la autora, 2017. 


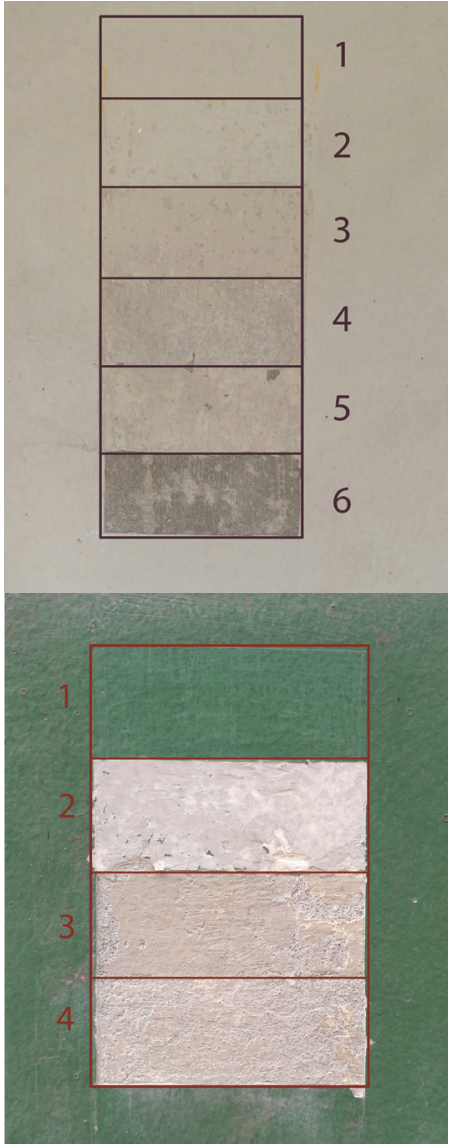

Figura 16. De arriba hacia abajo calas estratigráficas $\mathrm{N}^{\circ} 18$ y 19 respectivamente. Archivo fotográfico de la autora, 2017.

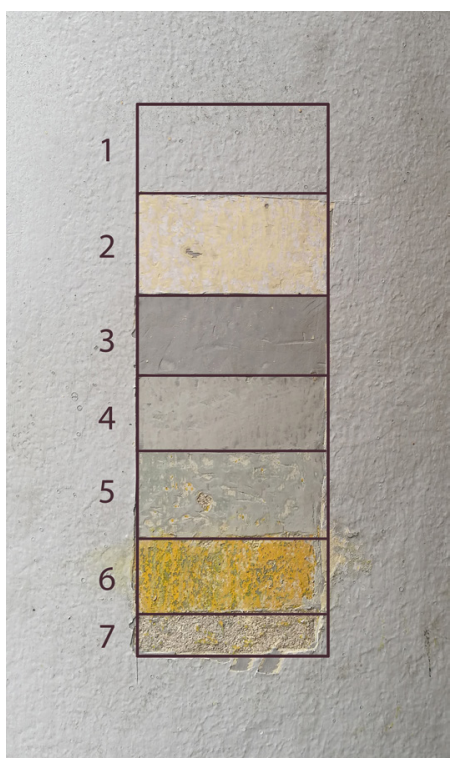

Figura 17. Cala estratigráfica Nro. 20. Archivo fotográfico de la autora, 2017. otro lado, en la capa 4 se observa un salto cromático drástico respecto a la capa anterior, virando a un color rojo. Sin embargo, posteriormente, se retoma los colores grises luminosos, para gradualmente cambiar hasta el blanco. En este caso, se observa que el soporte de cemento es coloreado, a diferencia de los soportes anteriores hallados

En cuanto al análisis del material, las capas 1 hasta la 4, presentan buena adherencia a las capas subyacentes. No obstante, las capas 5 y 6 tienen problemas de estabilidad y cohesión. Al igual que en otros casos anteriormente vistos, se observa que el color original se encuentra directamente en contacto con el soporte de cemento. (Ver figura 18)

- Cala estratigráfica Nro. 23

Ubicación: Fuste de columna circular

En esta cala se encontraron 10 capas, 9 de ellas corresponden a diversos momentos cromáticos y la última (capa 10) corresponde al soporte de cemento.

Según el análisis cromático, se puede ver una predominancia de los colores grises y casi en igual número, le siguen los tonos amarillos claros. Como capa original, se identificó que corresponde a un tono amarillo claro. Posteriormente a esa capa se produce un cambio hacia los colores grises, evidenciados por las capas 6,7 y 8 y a partir de la capa 5 se recupera el color amarillo (difiere de tonalidad con el amarrillo original). Nuevamente, a partir de la capa 2 se retoma un gris luminoso frío y culminar con una capa de un gris ligeramente más saturado que también se mantiene dentro de la temperatura de los tonos fríos.

En cuanto al análisis del material, se puede decir que la mayoría de las capas se encuentra estable y presentan buena adherencia. Sin embargo, la capa 5 se encuentra inestable y presenta desprendimientos. Nuevamente, de acuerdo con la evidencia, se concluye que la capa original está directamente en contacto con el soporte de cemento.

\section{Zona 13: Entrada de arco lado oeste}

- Cala estratigráfica Nro. 24

Ubicación: Muro de arco de ingreso

En la presente cala se encontraron 7 capas, de las cuales 6 corresponden a estratos de color y la última está referida al soporte de cemento.

De acuerdo con el análisis cromático se puede evidenciar que existe una marcada predominancia hacia los colores amarillos que se mantienen en varios momentos cromáticos. Por otro lado, entre la capa 6 y la capa 5 ocurre un cambio muy resaltante a nivel cromático pues del amarillo pastel se vira hacia un rojo siena intenso y posteriormente se retoma el cromatismo de los amarillos apastelados, para finalmente en la última capa, virar hacia el blanco. El color original corresponde a un amarillo cálido luminoso.

Finalmente, en lo que respecta al análisis del material se puede ver que la mayoría de las capas presentan buena adherencia. Sin embargo, el estrato original (capa 6) se muestra como pulverulento, delgado y con riesgo de desprendimiento. Esto aunado a la característica que se encuentra directamente sobre el soporte de cemento. (Ver Figura 19)

\section{Conclusiones}

1. Se han realizado en total 24 calas para poder abarcar un estudio de color significativo. Se han abordado las áreas representativas que pueden ser consideradas como puntos estratégicos. Para ello se tomó en cuenta la relevancia histórica de los espacios como la estructura en " $T$ ", la funcionalidad y la relevancia espacial en cuanto afluencia y uso de los mismos. 

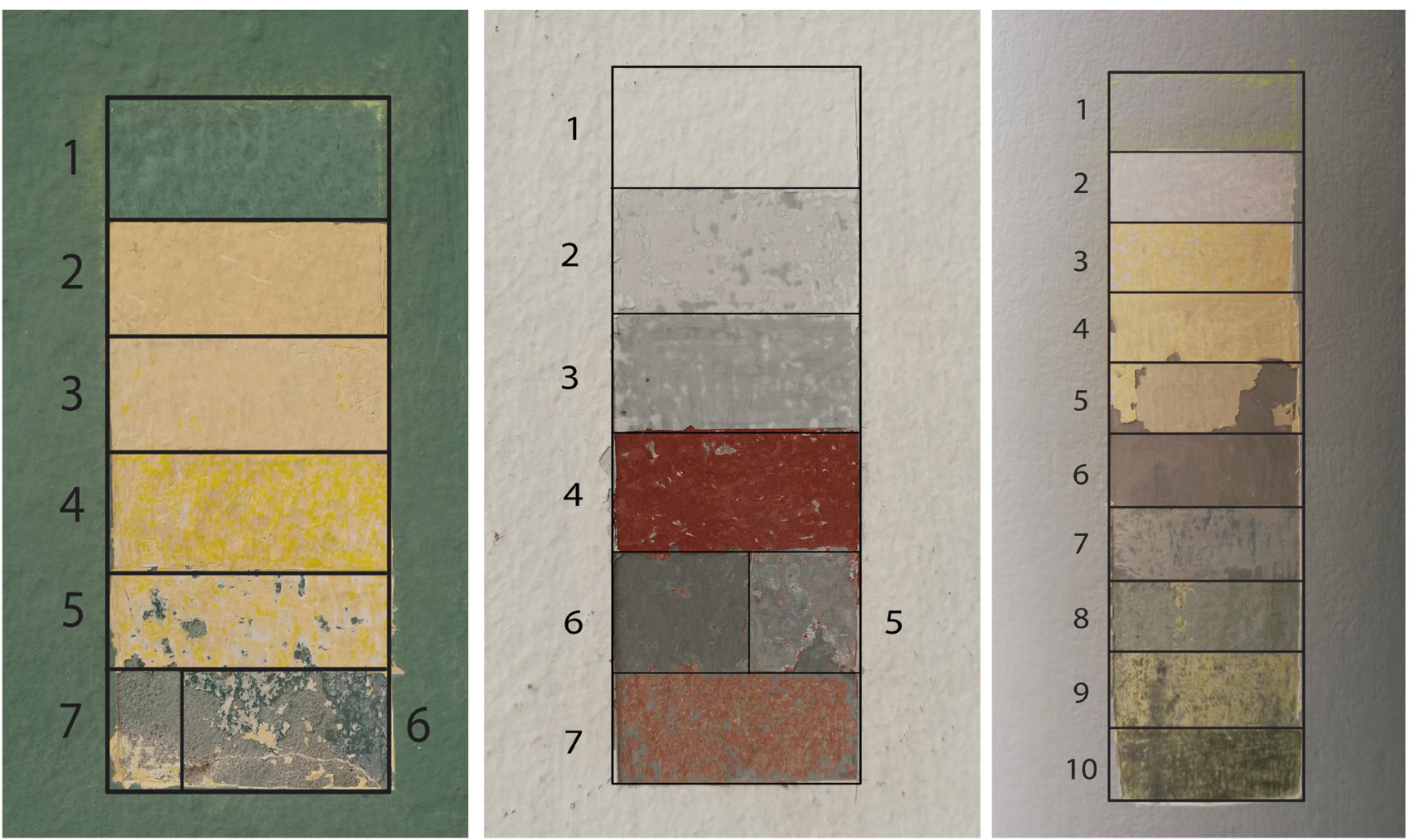

Figura 18. Calas estratigráficas Nro. 21, 22 y 23. Archivo fotográfico de la autora, 2017.

2. El mayor número de capas encontrado ha sido de 10 estratos. En líneas generales, las columnas son los sectores que presentan mayor cantidad de capas. Esto quiere decir que han sido los elementos más intervenidos a lo largo del tiempo.

3. Se han encontrado estratos de pintura originales que tienen colores muy saturados como amarillo, rojo, negro y azul metálico. Esto quiere decir que, en un comienzo, la facultad contaba con una paleta de color más saturada de colores puros. Se ha identificado dentro de la oferta en pinturas a nivel nacional, algunas que datan de épocas anteriores a la construcción del edificio de la Facultad de Arquitectura, Urbanismo y Artes de la UNI, como la fábrica de pinturas CPP (Compañía Peruana de Pinturas) que data de los años 30's. Posteriormente, otras empresas de pinturas empiezan a crecer en el mercado, como las pinturas de la marca Vencedor hace aproximadamente 50 años y es a partir de los años 80 's que esta oferta se amplía considerablemente hasta la actualidad con diversas marcas nacionales y extranjeras. Se entiende que la formulación de las pinturas ha ido cambiando con el paso del tiempo y a su vez, han ido mejorando en cuanto a la composición de los productos.

Las pinturas látex están formadas por una mezcla que contiene a los tintes, pigmentos o colorantes que se dispersan en un vehículo formado por resinas acrílicas y solventes y además contienen aditivos que mejoran el comportamiento tales como secantes, impermeabilizantes, entre otros. Por lo tanto, cada capa dependiendo de la marca de pintura a la que pertenezca, puede tener diferentes interacciones entre los estratos. Esto solo es visible cuando se realizan las calas estratigráficas y de alguna manera, este estudio puede ayudar a comprender y proyectar el comportamiento de cada capa a futuro.

4. Se ha identificado que muchas de las calas estratigráficas tienen tonalidades que priman en cuanto a gama de color, entre ellos los colores amarillos para muros y las tonalidades rojas para muros bajos. En el caso de las columnas, priman los colores amarillos, 


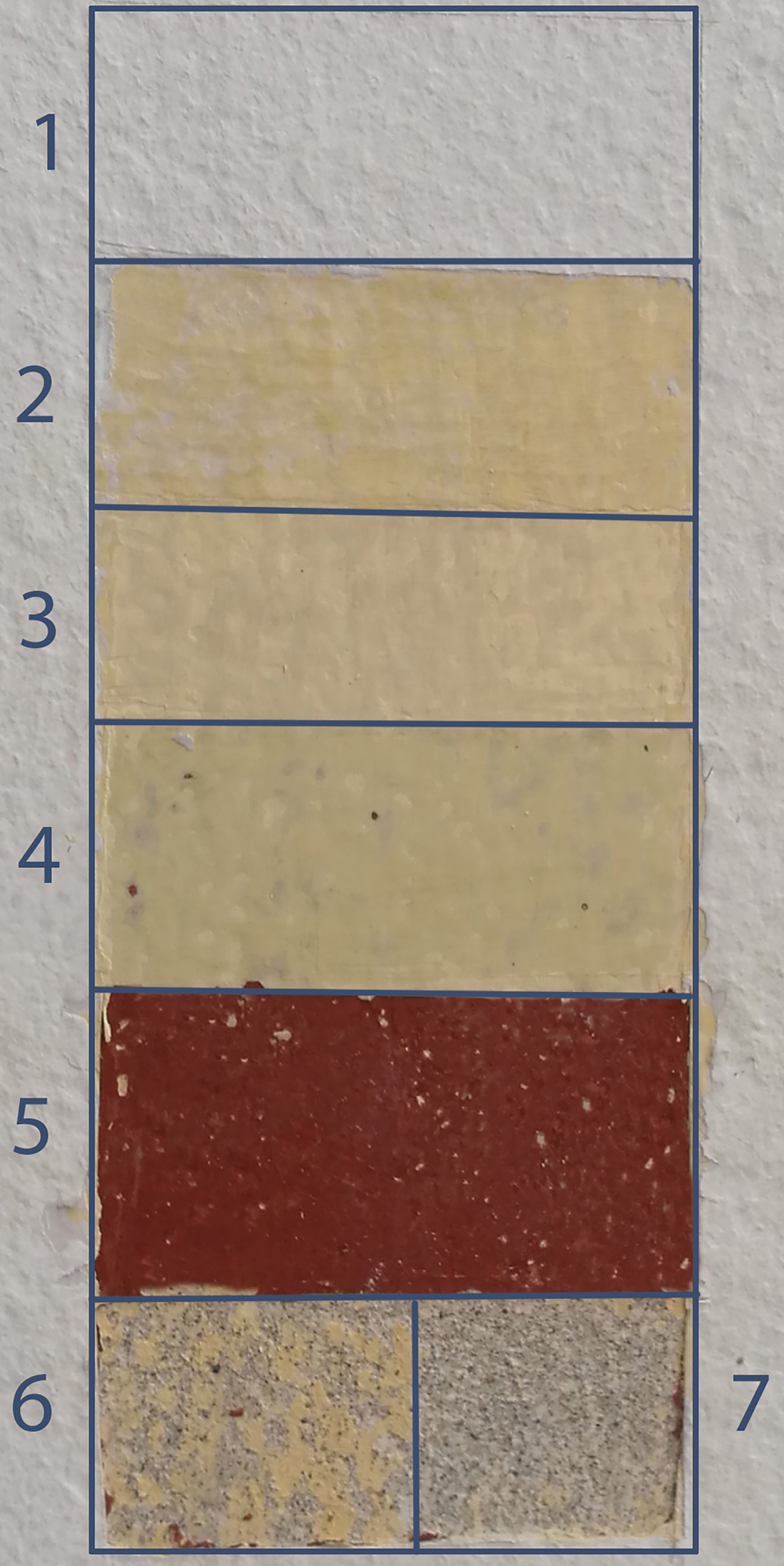

Figura 19. Cala estratigráfica Nro. 24.

Archivo fotográfico de la autora, 2017. 
Tabla 1. Zonas 1, 2 y 3 (calas 1 - 5)

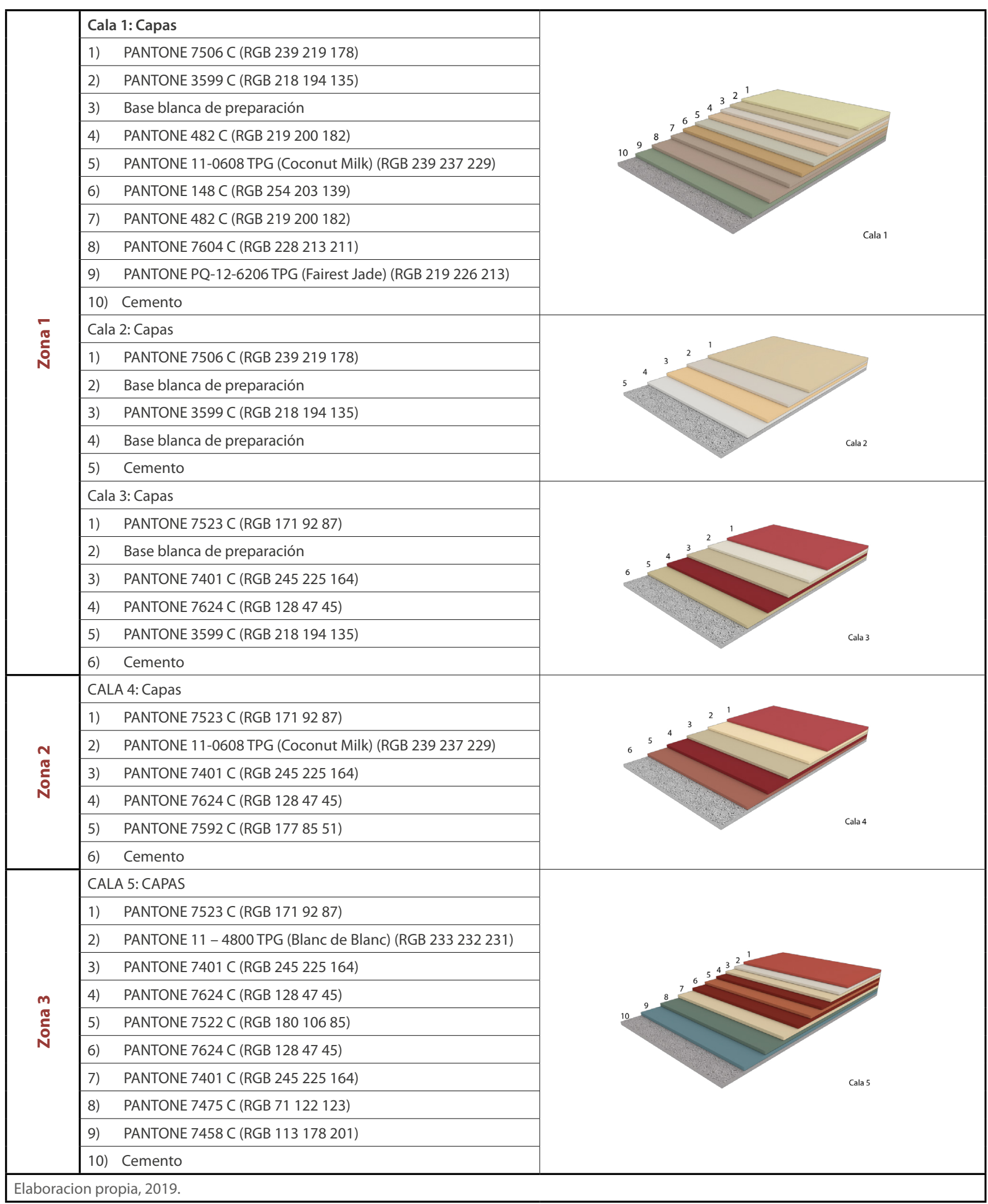


devenir Vol. 7, Nº14, JULIO-DICIEMBRE 2020, PP. 107-130 - EstudIOS | ISSN 2312-7562 | E-ISSN 2616-4949 UNIVERSIDAD NACIONAL DE INGGENIERÍA, LIMA

doi: https://doi.org/10.21754/devenir.v7i14.774

Tabla 2: Zonas 4, 5 y 6 (calas 6 - 11)

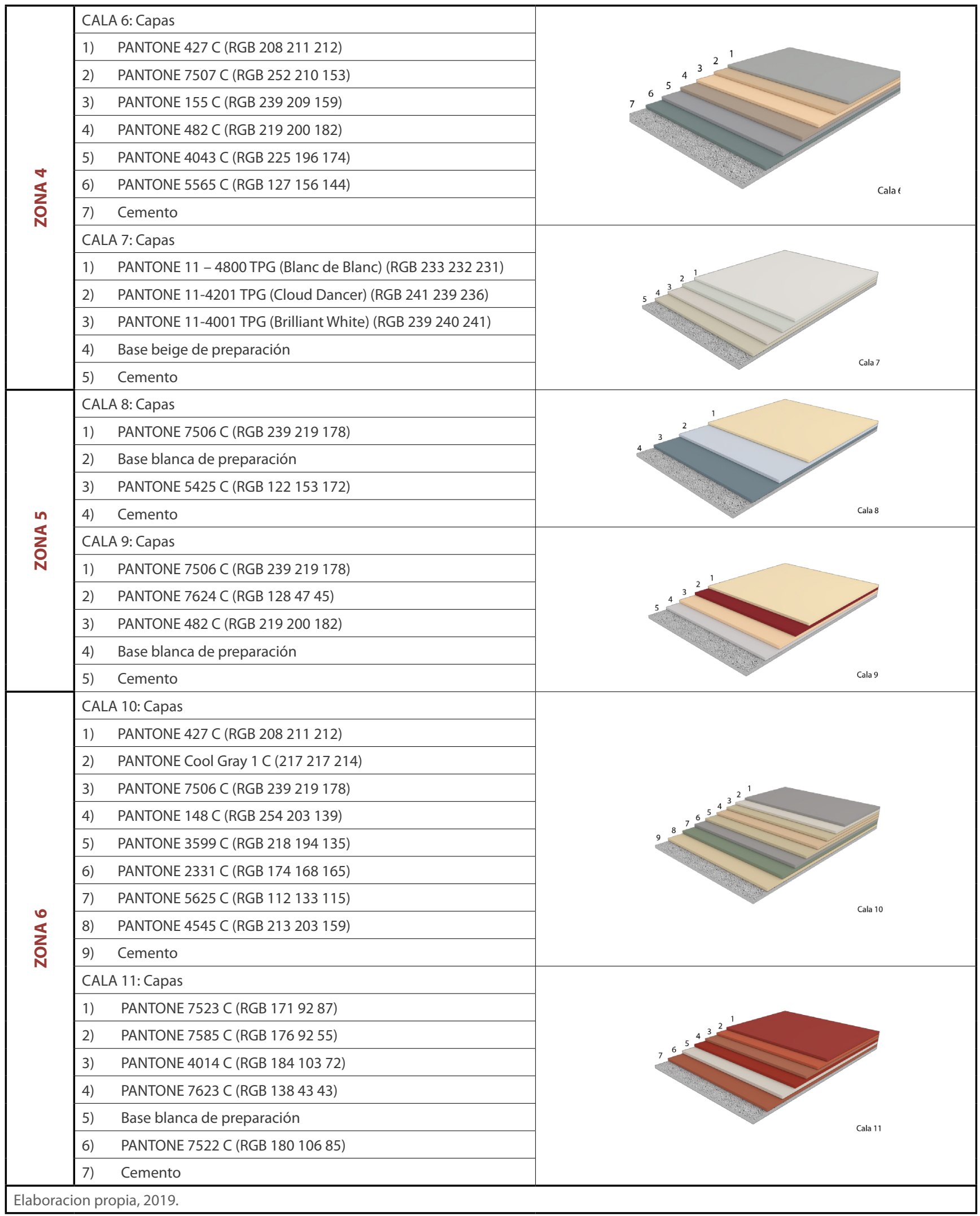


Tabla 3: Zonas 7, 8, 9 y 10 (calas 12 - 19)

\begin{tabular}{|c|c|c|}
\hline \multirow{7}{*}{ 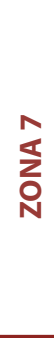 } & CALA 12: Capas & \\
\hline & 1) PANTONE 5545 C (RGB 67105 91) & \\
\hline & 2) PANTONE 5315 C (RGB 216215 223) & \\
\hline & 3) PANTONE 2015 C (RGB 248207 169) & \\
\hline & 4) PANTONE 712 C (RGB 252200 155) & \\
\hline & 5) PANTONE $102 \mathrm{C}$ (RGB 252227 0) & Cala 12 \\
\hline & 6) Cemento & \\
\hline \multirow{16}{*}{$\begin{array}{l}\infty \\
\text { ¿ } \\
\text { ○ }\end{array}$} & CALA 13: Capas & \multirow[b]{5}{*}{ Cala 13} \\
\hline & PANTONE 5545 C (RGB 67105 91) & \\
\hline & 2) PANTONE 5565 C (RGB 127156 144) & \\
\hline & 3) PANTONE 419 C (RGB 3335 34) & \\
\hline & 4) Cemento & \\
\hline & CALA 14: Capas & \multirow[b]{5}{*}{ Cala 14} \\
\hline & 1) PANTONE 5545 C (RGB 67105 91) & \\
\hline & 2) PANTONE 11 - 4800 TPG (Blanc de Blanc) (RGB 233232 231) & \\
\hline & 3) PANTONE 485 (RGB 21841 28) & \\
\hline & 4) Cemento & \\
\hline & CALA 15: Capas & \multirow{6}{*}{ Cala 15} \\
\hline & 1) PANTONE 5545 C (RGB 67105 91) & \\
\hline & 2) PANTONE 5565 C (RGB 127156 144) & \\
\hline & PANTONE 419 C (RGB 3335 34) & \\
\hline & 4) PANTONE 2331 C (RGB 174168 165) & \\
\hline & 5) Cemento & \\
\hline \multirow{15}{*}{$\begin{array}{l}a \\
\vdots \\
\text { zo }\end{array}$} & CALA 16: Capas & \multirow{7}{*}{ Cala 16} \\
\hline & 1) PANTONE 5545 C (RGB 67105 91) & \\
\hline & 2) PANTONE 5315 C (RGB 216215 223) & \\
\hline & 3) PANTONE 712 C (RGB 252200 155) & \\
\hline & 4) PANTONE 7506 C (RGB 239219 178) & \\
\hline & 5) PANTONE 102 C (RGB 252227 0) & \\
\hline & 6) Cemento & \\
\hline & CALA 17: Capas & \multirow{8}{*}{ Cala 17} \\
\hline & 1) PANTONE 427 C (RGB 208211 212) & \\
\hline & 2) PANTONE 7507 C (RGB 252210 153) & \\
\hline & 3) PANTONE 482 C (RGB 219200 182) & \\
\hline & 4) PANTONE 4043 C (RGB 225196 174) & \\
\hline & 5) PANTONE 5565 C (RGB 127156 144) & \\
\hline & 6) PANTONE 4545 C (RGB 213203 159) & \\
\hline & 7) Cemento & \\
\hline \multirow{7}{*}{$\begin{array}{l}\frac{0}{\leq} \\
\frac{1}{z} \\
\text { O }\end{array}$} & CALA 18: Capas & \multirow{7}{*}{ Cala 18} \\
\hline & 1) PANTONE 7527 C (RGB 214210 196) & \\
\hline & 2) PANTONE 12-0104 TPG (White Asparagus) (RGB 227222 201) & \\
\hline & 3) PANTONE PQ-12-0304 TPG (Whitecap Gray) (RGB 224215 198) & \\
\hline & 4) PANTONE 14-4002 TPG (Wind Chime) (RGB 202197 196) & \\
\hline & 5) PANTONE PQ-11-4301 TPG (Lily White) (RGB 227227 220) & \\
\hline & 6) Cemento & \\
\hline
\end{tabular}


devenir Vol. 7, N¹4, JULIO- DICIEMBRE 2020, PP. 107-130 - EsTUDIOS | ISSN 2312-7562 | E-ISSN 2616-4949 UNIVERSIDAD NACIONAL DE INGENIERÍA, LIMA

doi: https://doi.org/10.21754/devenir.v7i14.774

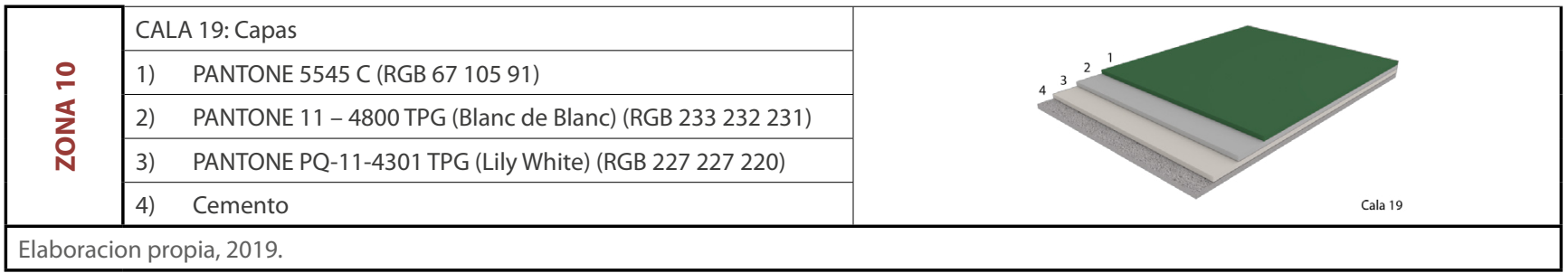

Tabla 4: Zona 11, 12 y 13. Fuente: autoría propia (2019)

\begin{tabular}{|c|c|c|}
\hline \multirow{8}{*}{$\begin{array}{l}\text { E } \\
\text { zo } \\
\text { ○ }\end{array}$} & CALA 20: Capas & \multirow{8}{*}{ Cala 20} \\
\hline & 1) PANTONE 427 C (RGB 208211 212) & \\
\hline & 2) PANTONE 7401 C (RGB 245225 164) & \\
\hline & 3) PANTONE 2331 C (RGB 174168 165) & \\
\hline & 4) PANTONE Cool Gray 3C (RGB 200201 199) & \\
\hline & 5) PANTONE 4274 C (RGB 176183 185) & \\
\hline & 6) PANTONE 102 C (RGB 252227 0) & \\
\hline & 7) Cemento & \\
\hline \multirow{27}{*}{$\begin{array}{l}\text { N } \\
\text { Z } \\
\text { Ò }\end{array}$} & CALA 21: Capas & \\
\hline & 1) PANTONE 5545 C (RGB 67105 91) & \\
\hline & 2) PANTONE 148 C (RGB 254203 139) & \\
\hline & 3) PANTONE 3599 C (RGB 218194 135) & \\
\hline & 4) PANTONE 102 C (RGB 252227 0) & \\
\hline & 5) PANTONE 148 C (RGB 254203 139) & \\
\hline & 6) PANTONE 567 C (RGB 2363 53) & Cala 21 \\
\hline & 7) Cemento & \\
\hline & CALA 22: Capas & \\
\hline & 1) PANTONE 11 - 4800 TPG (Blanc de Blanc) (RGB 233232 231) & \\
\hline & 2) PANTONE Cool Gray 1 C (RGB 217217 214) & \\
\hline & 3) PANTONE 428 C (RGB 193198 200) & \\
\hline & 4) PANTONE 7623 C (RGB 13843 43) & \\
\hline & 5) PANTONE 422 C (RGB 158162 162) & \\
\hline & 6) PANTONE Cool Gray 9 C (RGB 117120 123) & Cala 22 \\
\hline & 7) Cemento coloreado rojizo & \\
\hline & CALA 23: Capas & \\
\hline & 1) PANTONE 427 C (RGB 208211 212) & \\
\hline & 2) PANTONE Cool Gray 1 C (RGB 217217 214) & \\
\hline & 3) PANTONE 148 C (RGB 254203 139) & \\
\hline & 4) PANTONE 3599 C (RGB 218194 135) & \\
\hline & 5) PANTONE 482 C (RGB 219200 182) & \\
\hline & 6) PANTONE 2331 C (RGB 174168 165) & \\
\hline & 7) PANTONE 428 C (RGB 193198 200) & 23 \\
\hline & 8) PANTONE 443 C (RGB 145157 157) & \\
\hline & 9) PANTONE 4545 C (RGB 213203 159) & \\
\hline & 10) Cemento & \\
\hline
\end{tabular}




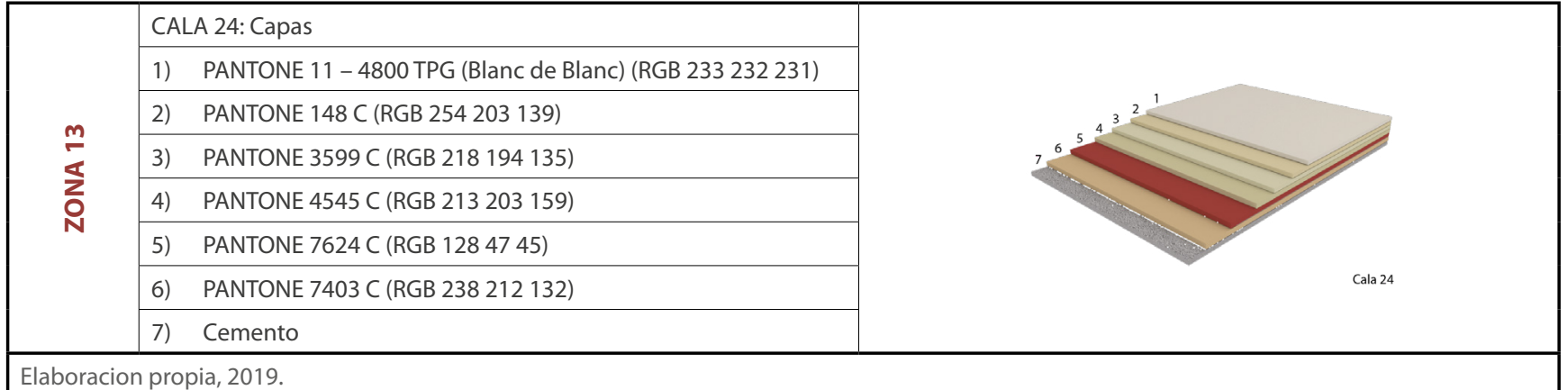

Tabla 5: Tabla resumen de resultados

\begin{tabular}{|c|c|c|c|}
\hline Zona & Calas & $\begin{array}{l}\text { Nro. de capas/ } \\
\text { cala }\end{array}$ & Código de color original \\
\hline \multirow{3}{*}{1} & Cala Nro. 1 & 10 & PANTONE PQ-12-6206 TPG (Fairest Jade) (RGB 219226 213) \\
\hline & Cala Nro. 2 & 5 & PANTONE 3599 C (RGB 218194 135) \\
\hline & Cala Nro. 3 & 6 & PANTONE 3599 C (RGB 218194 135) \\
\hline 2 & Cala Nro. 4 & 6 & PANTONE 7592 C (RGB 17785 51) \\
\hline 3 & Cala Nro. 5 & 10 & PANTONE 7458 C (RGB 113178 201) \\
\hline \multirow{2}{*}{4} & Cala Nro. 6 & 7 & PANTONE 5565 C (RGB 127156 144) \\
\hline & Cala Nro. 7 & 5 & PANTONE 3599 C (RGB 218194 135) \\
\hline \multirow{2}{*}{5} & Cala Nro. 8 & 4 & PANTONE 5425 C (RGB 122153 172) \\
\hline & Cala Nro. 9 & 5 & PANTONE 482 C (RGB 219200 182) \\
\hline \multirow{2}{*}{6} & Cala Nro. 10 & 9 & PANTONE 4545 C (RGB 213203 159) \\
\hline & Cala Nro. 11 & 7 & PANTONE 7522 C (RGB 180106 85) \\
\hline \multirow[t]{2}{*}{7} & Cala Nro. 12 & 6 & PANTONE 102 C (RGB 252227 0) \\
\hline & Cala Nro. 13 & 4 & PANTONE 419 C (RGB 3335 34) \\
\hline \multirow[t]{2}{*}{8} & Cala Nro. 14 & 4 & PANTONE 485 (RGB 21841 28) \\
\hline & Cala Nro. 15 & 5 & PANTONE 2331 C (RGB 174168 165) \\
\hline \multirow[t]{2}{*}{9} & Cala Nro. 16 & 6 & PANTONE 102 C (RGB 252227 0) \\
\hline & Cala Nro. 17 & 7 & PANTONE 4545 C (RGB 213203 159) \\
\hline \multirow[t]{2}{*}{10} & Cala Nro. 18 & 6 & PANTONE PQ-11-4301 TPG (Lily White) (RGB 227227 220) \\
\hline & Cala Nro. 19 & 4 & PANTONE PQ-11-4301 TPG (Lily White) (RGB 227227 220) \\
\hline \multirow[t]{2}{*}{11} & Cala Nro. 20 & 7 & PANTONE 102 C (RGB 252227 0) \\
\hline & Cala Nro. 21 & 7 & PANTONE 567 C (RGB 2363 53) \\
\hline \multirow[t]{2}{*}{12} & Cala Nro. 22 & 7 & PANTONE Cool Gray 9 C (RGB 117120 123) \\
\hline & Cala Nro. 23 & 10 & PANTONE 4545 C (RGB 213203 159) \\
\hline 13 & Cala Nro. 24 & 7 & PANTONE 7403 C (RGB 238212 132) \\
\hline
\end{tabular}


sin embargo, los cambios de color a lo largo del tiempo son también más marcados, existiendo una gran cantidad de contrastes en cuanto a tonos y matices de color.

5. En la cala Nro. 22 (entrada lado oeste del edificio de la FAUA-UNI) se ha identificado que la capa que corresponde al cemento es de color cálido, es decir, podría tratarse de un cemento coloreado con ocre. Otra hipótesis es que podría tratarse de un soporte de ladrillo. Sin embargo, no se han encontrado evidencias de la textura de las juntas de estos.

6. En la mayoría de los casos, las capas originales están dispuestas directamente sobre el cemento. Lo cual nos indica la técnica de pintado empleada pudo haber omitido la capa de preparación de la pared o en todo caso, dicha capa fue muy delgada de tal forma que logró tapar los poros para cumplir con el efecto impermeabilizante, sin llegar a formar un estrato propiamente dicho. Solo en algunos casos se ha podido identificar el empaste plástico de color blanco, pero éstos corresponden a momentos más modernos de la facultad.

7. Para la interpretación cromática con el uso de la carta de color Pantone ${ }^{\circledR}$, se ha respetado la denominación de los colores en su idioma de origen para facilitar su búsqueda. (Ver tablas 1, 2, 3, 4 y 5)

\section{Referencias}

Barros, J. (2010). La correlación de unidades estratigráficas en estructuras pictóricas. Valencia, España: Instituto Universitario de Restauración del Patrimonio de la Universidad Politécnica de Valencia.

Beingolea, J. (2010). El DAENI - El edificio, vitrina de la arquitectura moderna. HUACA Estudiantil, 51-58.

Carta del Restauro. (1972). (M. Martínez, trad.) Málaga, España.

Facho, A. (2008). HABITAR, Ambiente + Arquitectura + Ciudad: https://habitar-arq.blogspot. com/2008/09/facultad-de-arquitectura.html

López Soria, J. (2017). Breve historia de la UNI. Lima, Perú: Editorial Universitaria de la Universidad Nacional de Ingeniería.

Muñoz, L. (2008). Los valores del color aplicado a la reciente arquitectura. Imafronte (19-20), 251268. Murcia, España: Universidad de Murcia.

Pantone. (2019): https://www.pantone.com/color-consulting/about-pantone-color-institute 